\title{
What is the Role of Sea Surface Temperature in Modulating Cloud and Precipitation Properties over the Southern Ocean?
}

\author{
Yi Huang,,${ }^{\mathrm{a}, \mathrm{b}}$ Steven T. Siems,,${ }^{\mathrm{a}, \mathrm{b}}$ Michael J. MANTON, ${ }^{\mathrm{a}}$ DANIEl Rosenfeld, ${ }^{\mathrm{c}}$ \\ Roger Marchand, ${ }^{\mathrm{d}}$ Greg M. MCFARQuhar, ${ }^{\mathrm{e}}$ AND Alain Protat ${ }^{\mathrm{f}}$ \\ ${ }^{a}$ School of Earth, Atmosphere and Environment, Monash University, Melbourne, Victoria, Australia \\ ${ }^{\mathrm{b}}$ Australian Research Council Centre of Excellence for Climate System Science, \\ Monash University, Melbourne, Victoria, Australia \\ ${ }^{\mathrm{c}}$ Institute of Earth Sciences, Hebrew University, Jerusalem, Israel \\ ${ }^{\mathrm{d}}$ Department of Atmospheric Sciences, University of Washington, Seattle, Washington \\ ${ }^{\mathrm{e}}$ Department of Atmospheric Sciences, University of Illinois at Urbana-Champaign, Urbana, Illinois \\ ${ }_{\mathrm{f}}^{\mathrm{f}}$ Australian Bureau of Meteorology, Melbourne, Victoria, Australia
}

(Manuscript received 30 October 2015, in final form 21 July 2016)

\begin{abstract}
This study employs four years of spatiotemporally collocated A-Train satellite observations to investigate cloud and precipitation characteristics in relation to the underlying properties of the Southern Ocean (SO). Results show that liquid-phase cloud properties strongly correlate with the sea surface temperature (SST). In summer, ubiquitous supercooled liquid water (SLW) is observed over SSTs less than about $4^{\circ} \mathrm{C}$. Cloud-top temperature (CTT) and effective radius of liquid-phase clouds generally decrease for colder SSTs, whereas the opposite trend is observed for cloud-top height, cloud optical thickness, and liquid water path. The deduced cloud depth is larger over the colder oceans. Notable differences are observed between "precipitating" and "nonprecipitating" clouds and between different ocean sectors. Using a novel joint SST-CTT histogram, two distinct liquid-phase cloud types are identified, where the retrieved particle size appears to increase with decreasing CTT over warmer water (SSTs $>\sim 7^{\circ} \mathrm{C}$ ), while the opposite is true over colder water. A comparison with the Northern Hemisphere (NH) storm-track regions suggests that the ubiquitous SLW with markedly smaller droplet size is a unique feature for the cold SO (occurring where SSTs $<\sim 4^{\circ} \mathrm{C}$ ), while the presence of this cloud type is much less frequent over the $\mathrm{NH}$ counterparts, where the SSTs are rarely colder than about $4^{\circ} \mathrm{C}$ at any time of the year. This study also suggests that precipitation, which has a profound influence on cloud properties, remains poorly observed over the SO with the current spaceborne sensors. Large uncertainties in precipitation properties are associated with the ubiquitous boundary layer clouds within the lowest kilometer of the atmosphere.
\end{abstract}

\section{Introduction}

The Southern Ocean (SO), covering 15\% of Earth's surface, is a key component of Earth's climate system. Yet large cloud and solar radiation biases over the SO have been a long-standing problem in climate models and reanalysis products (Trenberth and Fasullo 2010; Bodas-Salcedo et al. 2014). Because of its critical

Supplemental information related to this paper is available at the Journals Online website: http://dx.doi.org/10.1175/ JCLI-D-15-0768.s1.

Corresponding author address: Yi Huang, School of Mathematical Sciences, Monash University, Clayton Campus, Wellington Road, Clayton, VIC 3800, Australia.

E-mail: vivian.huang@monash.edu influence, the SO has been highlighted by the U.S. National Science Foundation Advisory Committee for Geosciences under one of their four research frontiers for 2015-20 (NSF 2014).

Previous studies suggest that the greatest contribution to model cloud bias is an underestimate of cloud cover, especially that of optically thick low- and midaltitude clouds (Bodas-Salcedo et al. 2012, 2014), and an associated overestimate of precipitation (Franklin et al. 2013). Indications are that the model cloud bias is most pronounced in austral summer under relatively stable synoptic conditions (Williams et al. 2013). While these studies were able to diagnose the large-scale characteristics within which the model errors occur, they do not directly explore the underlying physical mechanisms that lead to these biases. Moreover, it remains an open question as to why the model biases tend to increase 
toward higher latitudes (Bodas-Salcedo et al. 2014), farther away from the storm tracks.

Our understanding of cloud and precipitation processes over the SO is limited due, to a significant degree, to sparse observations in this region. The dedicated field campaigns undertaken over the SO-the Aerosol Characterization Experiment (ACE-1; Bates et al. 1998) and the Southern Ocean Cloud Experiments I and II (SOCEX I and II; Boers et al. 1998) - are already 20 years old. Although isolated field projects were infrequently conducted in the past decade (e.g., Wofsy 2011; Huang et al. 2015a), the limited instrumentation and platforms have inhibited a significant advancement of knowledge.

In recent years, the multisatellite A-Train constellation (Stephens et al. 2002) with modern passive and active sensors has advanced the observations of a variety of atmospheric parameters and inspired a growing number of studies with a focus on SO clouds (e.g., Mace 2010; Haynes et al. 2011; Protat et al. 2014) and precipitation (e.g., Ellis et al. 2009; Stephens et al. 2010; Wang et al. 2015). For instance, McCoy et al. (2014a,b) used a composite of satellite-retrieved cloud properties to highlight the sensitivity of the calculated reflected shortwave radiation over the SO to the low cloud cover, partitioning of mixed-phase clouds, and cloud effective radius. Naud et al. (2014) employed A-Train observations to evaluate reanalysis products and found that the low-altitude cloud amounts over the SO were commonly underestimated, and that the large-scale characteristics $(850-\mathrm{hPa}$ wind speed and vertical velocity, precipitable water, and temperature), which are very similar between the reanalysis datasets, do not explain the differences in their lowcloud cover. It is suggested that the physical parameterizations are most likely the source of model deficiencies. A number of recent studies further suggest that the low- and midlevel clouds over the SO consist of a large amount of supercooled liquid water (SLW), particularly during austral summer (Hu et al. 2010; Morrison et al. 2011; Huang et al. 2012a,b). Huang et al. (2015b) show that the abundant SLW over the SO is a great contrast to the North Atlantic, where precipitation and glaciated clouds are more prevalent. They suggested that the summertime interhemisphere difference in the SLW occurrence is fundamentally controlled by thermodynamics.

The prevalence of SLW over the SO is also supported by limited ground-based (e.g., Kanitz et al. 2011) and in situ measurements over the mid- and high-latitude SO (Chubb et al. 2013) and over Antarctica (Grosvenor et al. 2012). A recent study by Bodas-Salcedo et al. (2016) highlighted the central role of SLW clouds to the shortwave radiation budget over the $\mathrm{SO}$, and the poor representation of these clouds in climate models, which leads to biases in simulated sea surface temperatures (SSTs). Other studies also argued that climate models generally have great difficulties in preserving sufficient SLW at mixed-phase cloud temperatures (Komurcu et al. 2014; Luo et al. 2015; McCoy et al. 2015b; Cesana et al. 2015) and do not reproduce the geographical distributions of liquid water path (e.g., Cheng and Xu 2015; Bodas-Salcedo et al. 2016).

Motivated by these findings, intense efforts have been made in recent years with the aim to improve the simulations of low clouds and thermodynamic phase over the SO, through development of more sophisticated physical and aerosol parameterizations (e.g., Xu and Cheng 2013; Walters et al. 2014; Forbes and Ahlgrimm 2014; Mulcahy et al. 2014). Yet recent simulations suggest that model biases in the SO remain excessively large (Grise et al. 2015; Bodas-Salcedo et al. 2016) and that some of the regional improvements are compromised by undesirable biases that developed elsewhere (e.g., Luo et al. 2015) or result from compensating errors (Huang et al. 2015a; Mason et al. 2015). These shortcomings underpin a pressing need for further investigation of cloud, aerosol, and precipitation processes in this remote region and, in particular, continued efforts to understand the physical processes that shape the observed and retrieved characteristics, including interactions between the atmosphere and the underlying oceans (Xie 2004).

Air-sea interactions occurs across a wide range of spatial scales (Minobe et al. 2008; White and Annis 2003; Park et al. 2006). Using global circulation models (GCMs), Inatsu and Hoskins (2004) concluded that the major determinant of the lower-troposphere storm track intensity over the SO was the enhanced midlatitude SST gradients, or polar front (Moore et al. 1999; Dong et al. 2006b). Small et al. (2014) confirmed this using a high-resolution GCM, and suggested that the enhanced baroclinicity and latent heat fluxes most likely contributed to the increase of storm activities over the SO. Smaller mesoscale oceanic eddies can influence turbulent heat fluxes and energy exchange, affecting winds, clouds, and rainfall patterns (Frenger et al. 2013; Villas Bôas et al. 2015). Moreover, Zábori et al. $(2012,2013)$ analyzed laboratory and in situ data of marine aerosols of the Arctic Ocean, noting a significant enhancement of sea salt aerosol concentration with decreasing water temperature. Coincidently, Chubb et al. (2016) showed in situ observations of a marked increase of cloud droplet number concentration and decrease of droplet size over the high-latitude SO, associated with increased surface wind speeds. These findings, albeit rudimentary, suggest that there may be an intrinsic link between the oceans and aerosol-cloud-precipitation processes across different scales.

In this study, we employ a range of A-Train satellite products to investigate cloud and precipitation 
TABLE 1. Summary of A-Train products and variables used in this study.

\begin{tabular}{|c|c|c|c|}
\hline Satellite & Product and version & Variable(s) & Spatial resolutions \\
\hline AMSR-E & $\begin{array}{l}\text { Level-3 daily ocean } \\
\text { product (versions } \\
4 \text { and 5) }\end{array}$ & SST and surface wind speed & $0.25^{\circ} \times 0.25^{\circ}$ \\
\hline \multirow[t]{3}{*}{$\begin{array}{l}\text { MODIS } \\
\quad \text { (onboard Aqua) }\end{array}$} & $\begin{array}{l}\text { Level-1 geolocation } \\
\text { product } \\
\text { (collection 6) }\end{array}$ & Latitude and longitude & $1 \times 1 \mathrm{~km}^{2}$ at nadir \\
\hline & \multirow[t]{2}{*}{$\begin{array}{l}\text { Level-2 cloud } \\
\text { products } \\
\text { (collection } 6)\end{array}$} & $\begin{array}{l}\text { Cloud-top temperature (CTT), cloud-top height } \\
\text { (CTH), cloud phase infrared (CPI; derived } \\
\text { from infrared channels; Baum et al. 2012), } \\
\text { and solar zenith angle } \theta_{0}\end{array}$ & $\begin{array}{l}5 \times 5 \mathrm{~km}^{2} \text { at nadir, oversampled } \\
\text { to } 1 \times 1 \mathrm{~km}^{2} \text { in collection } 6\end{array}$ \\
\hline & & $\begin{array}{l}\text { Cloud phase optical property (CPOP; derived } \\
\text { from shortwave and near-infrared channels; } \\
\text { Marchant et al. 2016); cloud effective radius } \\
\text { at 1.6-, 2.1-, and 3.7- } \mu \text { m channels }\left(r_{e_{-} 16}, r_{e_{-} 21} \text {, }\right. \\
\text { and } r_{\left.e_{-} 37\right)} \text {; cloud optical thickness (COT); cloud } \\
\text { water path (CWP); and cloud multilayer flag }\end{array}$ & $1 \times 1 \mathrm{~km}^{2}$ at nadir \\
\hline CALIPSO & $\begin{array}{l}\text { 1-km cloud layer } \\
\text { product } \\
\text { (version } 3.01 \text { ) }\end{array}$ & $\begin{array}{l}\text { Cloud thermodynamic phase, CTT, } \\
\text { and CTH (Powell et al. 2010; Hu et al. 2009) }\end{array}$ & 1-km horizontal \\
\hline CloudSat & $\begin{array}{l}\text { 2B-GEOPROF } \\
\text { product (versions } \\
4.02 \text { through } 4.04 \text { ) }\end{array}$ & Radar reflectivity & $\begin{array}{l}\text { 1.7- (along track) and } 1.4-\mathrm{km} \\
\text { (cross track) horizontal } \\
\text { and } 480-\mathrm{m} \text { vertical }\end{array}$ \\
\hline
\end{tabular}

properties in relation to the properties of the SO. Our aim is to statistically examine possible responses of cloud and precipitation properties to the underlying geophysical factors. In particular, our examination is focused on hydrometer properties that have direct contributions to the top-of-atmosphere radiation budget (McCoy et al. 2014a,b) and that can be retrieved readily from spaceborne observations.

\section{Datasets and methodology}

\section{a. Datasets}

A range of spatiotemporally matched cloud and precipitation properties obtained from multiple A-Train satellite products are examined to derive a 4-yr (2007-11) composite for the austral summer December-February (DJF) and winter June-August (JJA). Table 1 summarizes the various A-Train products used in this study. Note that while the main interest of this study is the SO, necessary comparisons are also made against the Northern Hemisphere $(\mathrm{NH})$ counterparts, with the boreal summer (winter) defined by JJA (DJF). The investigation areas are described in section $2 \mathrm{~b}$.

\section{1) AMSR-E}

The Advanced Microwave Scanning RadiometerEarth Observing System (AMSR-E) is a six-frequency, conically scanning, microwave radiometer onboard the Aqua satellite (Wentz et al. 2003). In this study we use the
SST retrievals from AMSR-E level-3 daily ocean products (versions 4 and 5). In this product, the global orbital data are mapped onto $0.25^{\circ} \times 0.25^{\circ}$ grid boxes. An assessment of AMSR-E SST accuracy in the SO by Dong et al. (2006a) suggests that this product has better temporal resolution and less bias relative to in situ observations (with a warm bias of $\sim 0.23^{\circ} \mathrm{C}$ in spring and summer) when compared against the retrievals from MODIS and the weekly Reynolds optimal interpolation.

\section{2) MODIS}

Level-2 cloud products (collection 6; Platnick et al. 2014) and level-1 geolocation products from the ModerateResolution Imaging Spectroradiometer (MODIS) instrument onboard Aqua are employed. A summary of the variables examined is given in Table 1 . Note that compared to collection 5 of the cloud products, a number of major changes have been made in collection 6 with the aim of improving retrieval accuracy. For cloud optical and microphysical retrievals, the most pertinent changes include (i) the reflectance ratio method for retrieving cloud phase optical property being replaced with separate ice and liquid retrievals, using a new trispectral infrared phase product, (ii) improvements to pixel-level retrieval uncertainty calculations, and (iii) new cloud radiative transfer code and lookup table approaches. A comprehensive description of the collection 6 cloud products can be found in Platnick et al. (2014).

In addition to the retrieved variables, we also calculate the cloud droplet number concentration $N_{d}$ for 
liquid-phase clouds using the method given by Grosvenor and Wood (2014, hereafter GW14), which was modified from the original method in Bennartz (2007, hereafter B07). The equation for calculating $N_{d}$ is

$$
N_{d}=\frac{2 \sqrt{10}}{k \pi Q^{3}}\left[\frac{c_{w} \mathrm{COT}}{\rho_{L}\left(r_{e \_21}\right)^{5}}\right]^{1 / 2},
$$

where COT is cloud optical thickness, $r_{e_{-} 21}$ is effective radius retrieved from the $2.1-\mu \mathrm{m}$ channel, $k$ relates the volume mean radius to the effective radius of a droplet size distribution (which depends on the width of the droplet size distribution), and a constant for $k$ of 0.8 is adopted in this study, as it was in GW14. Also, $Q$ is the scattering efficiency, and is taken to be 2 (effectively assuming droplets are small enough to be in the geometrical optics limit); $\rho_{L}$ is liquid water density $\left(1.0 \times 10^{3} \mathrm{~kg} \mathrm{~m}^{-3}\right)$; and $c_{w}$ is the temperature-dependent condensation rate (in $\mathrm{kg} \mathrm{m}^{-4} ; c_{w}$ in reality also depends on pressure, but to a much lesser extent than for temperature). In B07, $c_{w}$ was set to $80 \%$ of its adiabatic value at temperatures greater than $270 \mathrm{~K}$, and only marine boundary layer clouds were examined. In our analysis, we use $c_{w}$ ( $80 \%$ of adiabatic) but extended lower to $233 \mathrm{~K}$ (using MODIS cloud-top temperature) to allow the calculation of $N_{d}$ for SLW. Albrecht et al. (1990) and Ahmad et al. (2013, hereafter A13) give two alternative derivations of the quantity of $c_{w}$, but they do not discuss the superiority of any particular approach. Comparison of the $c_{w}^{1 / 2}$ [note the square root in Eq. (1)] curves derived from A13 and B07 suggests that the differences are negligible for temperature below $283 \mathrm{~K}$, although the A13 curve may be more accurate (see discussion in section S1 of the supplementary material). A comprehensive error estimate for $N_{d}$ is given in GW14 and B07 and here we refrain from an extensive discussion of the uncertainties. However, we should point out that in addition to the various assumptions applied, the error budget of the equation is mainly driven by the uncertainties in $r_{e \_21}(15 \%-20 \%)$ and COT $(\sim 20 \%)$, as suggested in GW14. Accordingly, $N_{d}$ is expected to be 5 times more sensitive to errors in $r_{e_{-} 21}$ than in COT (following the power relationships). As such, disproportionally larger uncertainties are expected for $N_{d}$ compared to other retrieved variables. Note that while the $80 \%$ adiabatic assumption may cause some temperature-dependent biases, its contribution to the overall error budget is relatively small.

\section{3) CALIPSO}

The Cloud-Aerosol Lidar and Infrared Pathfinder Satellite Observations (CALIPSO) satellite carries the Cloud-Aerosol Lidar with Orthogonal Polarization
(CALIOP), a nadir-viewing two-wavelength (532 and $1064 \mathrm{~nm}$ ), polarization-sensitive lidar (Liu et al. 2009) and a three-channel infrared radiometer. The level-2 version 3.01 cloud and aerosol layer product (Powell et al. 2010) contains a map of all the separate layers detected by CALIPSO along with an identification of cloud and aerosol types (and subtypes) and cloud thermodynamic phase averaged to $1-\mathrm{km}$ horizontal resolution. Cloud phase is retrieved with the algorithm described in $\mathrm{Hu}$ et al. (2009), using lidar attenuated backscatter and depolarization ratio. Temperature is needed by this algorithm and is obtained from the Goddard Earth Observing System Model version 5 data product, which is provided to the CALIPSO project by the Global Modeling and Assimilation Office Data Assimilation System. CALIOP is sensitive to optically tenuous layers and becomes fully attenuated in the presence of clouds with optical thickness greater than about 3 (Hu et al. 2009).

\section{4) CLOUdSAT}

CloudSat carries a $94-\mathrm{GHz}$ cloud profiling radar (CPR; Im et al. 2006), which is optimized for vertically profiling clouds through the atmosphere and is sensitive to light rain and drizzle, as well as clouds. The CPR has a vertical resolution of $480 \mathrm{~m}$ (240-m sampling) and an along-track (cross track) resolution of $1.7 \mathrm{~km}(1.4 \mathrm{~km})$. The level-2 2B-GEOPROF product includes a cloud mask that identifies the location of hydrometeors in individual radar profiles, as well as the radar reflectivity of identified clouds (Marchand et al. 2008). A known issue with CloudSat is that radar bins within $750 \mathrm{~m}$ of the ocean surface suffer from surface clutter contamination (Marchand et al. 2008). Accordingly, radar bins within the lowest kilometer are not reliable and hence are excluded in this analysis. This limitation may lead to an underestimate in the frequencies of occurrence of cloud and light precipitation within the marine boundary layer. Nevertheless, CloudSat is arguably the best spaceborne active sensor for global precipitation detection for the period studied.

\section{b. Methodology}

\section{1) InVESTIGATION AREAS}

Does a statistically significant relationship between the retrieved cloud properties and the underlying SO SST exist? To address this question, we first divide a Southern Hemisphere belt (SHB; $50^{\circ}-60^{\circ} \mathrm{S}$ ) into $3610^{\circ} \times 10^{\circ}$ boxes, and examine the box-mean (spatiotemporal average) cloud properties against the mean values of several geophysical parameters, including SST. This assessment, albeit simple, provides a first-order 
(a) SST Summer Composite

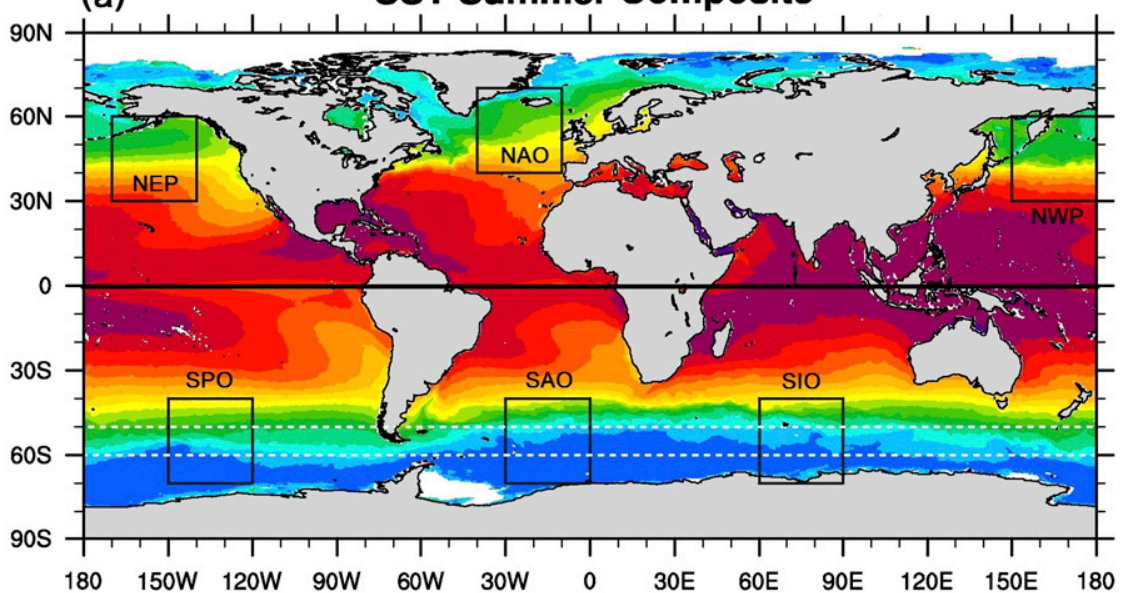

(b)

SST Winter Composite

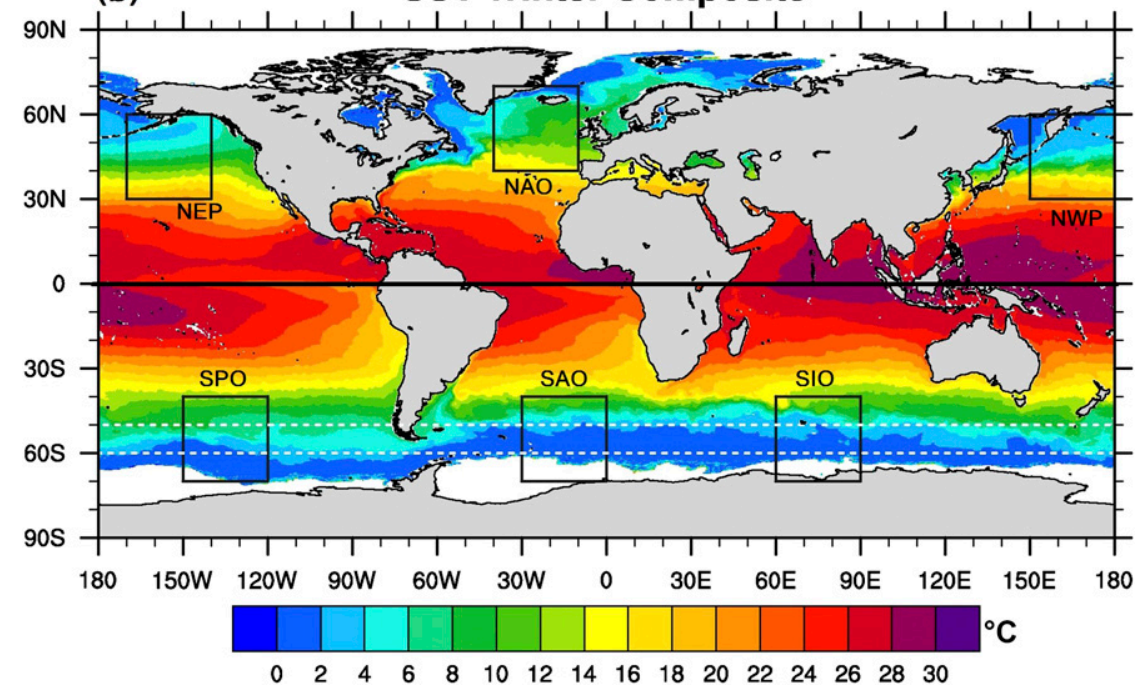

FIG. 1. AMSR-E derived 4-yr (2007-11) mean SST composite for both hemispheres, showing (a) boreal and austral summer together on the same plot and (b) boreal and austral winter together on the same plot. Austral (boreal) summer is defined by DJF (JJA), while austral (boreal) winter is defined by JJA (DJF). The SHB is the region between the two white dashed lines. The three ocean sectors over the SO (SIO, SPO, and SAO) and the Northern Hemisphere [NWP, northeast Pacific (NEP), and North Atlantic Ocean (NAO)] examined in this study are also denoted.

estimate of any impact that the sea surface may exert on the overlying cloud systems. Note that while the solar forcing is equal in each of the 36 boxes, there may be differences in cloud properties between the ocean sectors due to factors other than SST. This "box mean" approach also provides little insight into meridional variations.

To address these concerns, as a second step, we examine three climatically important SO sectors (Fig. 1) in more detail: the south Indian Ocean (SIO; $40^{\circ}-70^{\circ} \mathrm{S}, 60^{\circ}-90^{\circ} \mathrm{E}$ ), South Pacific Ocean (SPO; $\left.40^{\circ}-70^{\circ} \mathrm{S}, 120^{\circ}-150^{\circ} \mathrm{W}\right)$, and South Atlantic Ocean (SAO; $\left.40^{\circ}-70^{\circ} \mathrm{S}, 0^{\circ}-30^{\circ} \mathrm{W}\right)$.
Each of these sectors is further broken down into three subsectors, with each covering $10^{\circ}$ longitude and $30^{\circ}$ latitude. We compare intersector and subsector differences to examine the degree to which sector differences may be a response to SST differences, as well as to focus on meridional variation in each subregion.

\section{2) DATA COLLOCATION AND REMAPPING}

A key step for deriving meaningful information from multi-instrumental observations is to ensure that the retrieved variables are coordinated such that they are observing the same area of the atmosphere and the 
TABLE 2. Correlation coefficients of the mean cloud properties and selected geophysical parameters over SHB for summer (DJF). Statistical significance at $99 \%(90 \%)$ confidence level is indicated by two asterisks (one asterisk). Values in the parentheses are the results when the three Patagonian boxes are excluded.

\begin{tabular}{|c|c|c|c|c|}
\hline & Mean SST & Mean latitude of polar front & Mean latitude of max SST gradient & Mean surface wind speed \\
\hline \multicolumn{5}{|l|}{ CPI } \\
\hline RF (liquid) & $0.310(0.831 * *)$ & $0.289(0.810 * *)$ & $0.313(0.411)$ & $0.342(0.179)$ \\
\hline $\mathrm{RF}$ (ice) & $0.218(-0.044)$ & $0.208(-0.077)$ & $0.039(-0.079)$ & $0.472 *(0.371)$ \\
\hline RF (uncertain) & $0.721 * *(0.773 * *)$ & $0.680 * *(0.735 * *)$ & $0.415^{*}\left(0.436^{*}\right)$ & $0.067(0.028)$ \\
\hline CTT (liquid) & $0.964 * *(0.968 * *)$ & $0.889 * *(0.887 * *)$ & $0.459 * *(0.518 * *)$ & $0.082(0.227)$ \\
\hline CTT (ice) & $0.294(0.301)$ & $0.133(0.141)$ & $0.036(0.053)$ & $0.359 *(0.284)$ \\
\hline CTT (uncertain) & $0.651 * *(0.703 * *)$ & $0.523 * *(0.576 * *)$ & $0.148(0.140)$ & $0.107(0.091)$ \\
\hline \multicolumn{5}{|l|}{ CPOP } \\
\hline RF (liquid) & $0.572 * *(0.662 * *)$ & $0.482 * *(0.489 * *)$ & $0.075(0.235)$ & $0.346(0.031)$ \\
\hline RF (ice) & $0.571 * *(0.657 * *)$ & $0.479 * *(0.484 * *)$ & $0.046(0.215)$ & $0.358(0.047)$ \\
\hline RF (uncertain) & $0.435 *(0.379 *)$ & $0.403(0.301)$ & $0.384(0.277)$ & $0.152(0.417 *)$ \\
\hline CTT (liquid) & $0.776 * *(0.881 * *)$ & $0.759 * *(0.865 * *)$ & $0.526 * *(0.559 * *)$ & $0.141(0.157)$ \\
\hline CTT (ice) & $0.008(0.009)$ & $0.104(0.083)$ & $0.090(0.115)$ & $0.351(0.306)$ \\
\hline CTT (uncertain) & $0.046(0.021)$ & $0.057(0.084)$ & $0.130(0.139)$ & $0.441 *(0.392)$ \\
\hline$r_{e 21}$ (liquid) & $0.923 * *\left(0.936^{* *}\right)$ & $0.789 * *(0.792 * *)$ & $0.353(0.386)$ & $0.418 *\left(0.485^{*}\right)$ \\
\hline$r_{e_{-} 21}($ ice $)$ & $0.331(0.256)$ & $0.286(0.208)$ & $0.061(0.056)$ & $0.508 * *(0.378)$ \\
\hline$r_{e_{-} 21}$ (uncertain) & $0.065(0.407 *)$ & $0.049\left(0.409^{*}\right)$ & $0.282(0.289)$ & $0.610^{* *}\left(0.748^{* *}\right)$ \\
\hline
\end{tabular}

underlying surface. For collocating AMSR-E, MODIS, CALIPSO, and CloudSat observations, a principle of nearest neighbor within a $10-\mathrm{km}$ radius is adopted. The algorithm requires the availability of all the instruments, although not all the variables examined could be successfully retrieved at the same time. As a first step, each CALIPSO footprint is chosen to be the center for the collocation. The mapping algorithm then searches for the nearest footprints from individual CloudSat, MODIS, and AMSR-E samples, within a $10-\mathrm{km}$ radius surrounding the referred CALIPSO footprint. Note that in so doing, we have assumed that the diurnal variability of SST is relatively weak (Gille 2012) so that the daily gridmean AMSR-E SSTs are reused for all the CALIPSO, CloudSat, and MODIS overpasses in the same day. We have also tested the sensitivity of the statistics to the choice of collocation radius and found that the results are largely unaffected when a $5-\mathrm{km}$ radius is used. It should be pointed out that after a battery anomaly in 2011, CloudSat no longer maintains tight formation with CALIPSO, although it returned to A-Train in May 2012. In addition, AMSR-E stopped working in October 2011. As a result, it is only possible to construct the collocated AMSR-E-MODIS-CALIPSO-CloudSat (AMCC) dataset for a limited period from 2006 to early 2011.

\section{3. "Bulk" cloud characteristics over the SHB}

A 4-yr summertime daily mean SST composite is shown in Fig. 1a. In general, the SH SSTs are colder than the NH counterparts for the same latitude bands during the respective summer and winter. The oceanic polar front is a pronounced component in the SO midlatitudes, associated with the strongest meridional SST gradients. This feature is most evident in the SIO and SAO sector, and is associated with enhanced baroclinic instability there (Hoskins and Hodges 2005). To the south of the current, the SST gradient becomes weaker, leaving a vast area being colder than about $4^{\circ} \mathrm{C}$. The SST gradients in the $\mathrm{NH}$ oceans, on the other hand, are weaker. SSTs less than $4^{\circ} \mathrm{C}$ are only evident in the highlatitude oceans of the Arctic. The wintertime composite is shown in Fig. 1b. As expected, the NH mean SSTs during winter are notably colder than the $\mathrm{NH}$ mean SSTs in summer, such that the seasonal difference (summer minus winter) is more notable in the NH than $\mathrm{SH}$. In the SO, while the extension of the Antarctic sea ice is noticeable, seasonality of the mean SST pattern is weak.

Correlation coefficients for a variety of cloud properties over the 36 boxes and the box-mean SSTs are shown in Tables 2 and 3 for summer and winter, respectively. An example is presented in Fig. 2. The most notable feature, perhaps, is that there exists a marked correlation between the liquid-phase cloud properties (most pronouncedly CTT and $r_{e_{2} 1}$ ) and the underlying SST. The cloud phase relative frequencies of occurrence (RF) and SSTs correlate even better in winter. There appears to be, however, three outliers, which are the three boxes to the south of Patagonia in South America $\left(50^{\circ}-60^{\circ} \mathrm{S}, 50^{\circ}-80^{\circ} \mathrm{W}\right)$. These regions are generally characterized by lower RFs and relatively colder CTTs for liquid-phase clouds, which may be a response to the air outflow from the Andes and the 
TABLE 3. As in Table 2, but for winter (JJA).

\begin{tabular}{|c|c|c|c|c|}
\hline & Mean SST & Mean latitude of polar front & Mean latitude of max SST gradient & Mean surface wind speed \\
\hline \multicolumn{5}{|l|}{ CPI } \\
\hline RF (liquid) & $0.827 * *(0.893 * *)$ & $0.820 * *(0.887 * *)$ & $0.390(0.460)$ & $0.201(0.250)$ \\
\hline RF (ice) & $0.454 * *(0.612 * *)$ & $0.446 * *(-0.607 * *)$ & $0.247(0.392)$ & $0.059(0.185)$ \\
\hline $\mathrm{RF}$ (uncertain) & $0.899 * *(0.898 * *)$ & $0.895 * *(0.891 * *)$ & $0.389(0.383)$ & $0.275(0.236)$ \\
\hline CTT (liquid) & $0.953 * *(0.952 * *)$ & $0.907 * *(0.907 * *)$ & $0.410 *(0.390)$ & $0.133(0.100)$ \\
\hline CTT (ice) & $0.646 * *(0.663 * *)$ & $0.665 * *(0.666 * *)$ & $0.249(0.302)$ & $0.350(0.226)$ \\
\hline CTT (uncertain) & $0.827 * *(0.901 * *)$ & $0.776^{* *}\left(0.875^{* *}\right)$ & $0.434 *(0.460 *)$ & $0.067(0.046)$ \\
\hline \multicolumn{5}{|l|}{ CPOP } \\
\hline RF (liquid) & $0.150(0.068)$ & $0.173(0.065)$ & $0.224(0.111)$ & $0.172(0.139)$ \\
\hline $\mathrm{RF}$ (ice) & $0.187(0.005)$ & $0.209(0.005)$ & $0.240(0.143)$ & $0.184(0.126)$ \\
\hline $\mathrm{RF}$ (uncertain) & $0.545 *(0.764 * *)$ & $0.514 *\left(0.735^{* *}\right)$ & $0.141(0.343)$ & $0.112(0.211)$ \\
\hline CTT (liquid) & $0.536 *(0.810 * *)$ & $0.483^{*}\left(0.766^{* *}\right)$ & $0.070(0.238)$ & $0.063(0.121)$ \\
\hline CTT (ice) & $0.478 *(0.467 *)$ & $0.379(0.371)$ & $0.215(0.195)$ & $0.159(0.165)$ \\
\hline CTT (uncertain) & $0.655 * *(0.645 * *)$ & $0.611 * *(0.574 * *)$ & $0.290(0.238)$ & $0.442 *(0.363)$ \\
\hline$r_{e \_21}$ (liquid) & $0.639 * *(0.674 * *)$ & $0.579 * *(0.643 * *)$ & $0.448 *(0.435 *)$ & $0.395 *(0.348)$ \\
\hline$r_{e_{2} 21}($ ice $)$ & $0.340(0.288)$ & $0.211(0.152)$ & $0.022(0.120)$ & $0.227(0.195)$ \\
\hline$r_{e-21}$ (uncertain) & $0.496^{*}\left(0.758^{* *}\right)$ & $0.427 *(0.702 * *)$ & $0.075(0.281)$ & $0.181(0.131)$ \\
\hline
\end{tabular}

coastal currents. Accordingly, cloud properties over these areas may not be a good representation for the open SO.

Ice (and "uncertain" phase) cloud properties, on the other hand, are only weakly correlated with SST. This is not surprising given that the bulk of these glaciated (including uncertain) clouds reside in the free troposphere and experience strong zonal winds. These clouds can readily advect $10^{\circ}-15^{\circ}$ longitude a day, decoupling them from the underlying SST. With the exclusion of the three outliers, we use a Student's $t$ test to examine the robustness of the correlations between the cloud properties and the SST. The results indicate that nearly all the correlations for the liquid-phase cloud properties are statistically significant at a $99 \%$ confidence level. Note that within the context of the statistic test, the 36 boxes are treated as independent samples, while in reality the seasonal values in the neighboring boxes may be correlated.

In addition to the SST, we also considered the correlation of the average cloud properties against a number of other geophysical parameters including: the mean polar front latitude, mean latitude of the maximum SST gradient, and mean surface wind speed, as these parameters are known to play an important role in air-sea interactions. Overall, no substantial connections are found, with the exception of the mean polar front latitude. This, however, is not surprising given that the polar front location per se is a derivative of SST. Nevertheless, we found that the strongest correlations are with the mean SST.

Overall, the simple analysis above suggests that there may be a strong link between the SST and the overlying liquid-phase clouds over the SO. Built on this understanding, in subsequent sections we further explore the meridional and zonal variations of the liquid-phase cloud properties in greater details, where the analysis is performed on a regional basis.

\section{Cloud properties of different ocean sectors using synergetic multisatellite observations}

Motivated by the findings in section 3, in this section, we further examine the SST-cloud property correlations on a regional basis, using the AMCC dataset. Henceforth we focus exclusively on liquid-phase clouds, given their central role in understanding and simulating the SO environment (Bodas-Salcedo et al. 2016), and their strong geophysical dependence, in line with the spatial distribution of the mean radiation biases in GCMs. Because of the frequently large solar zenith angle over high-latitude regions in the cold seasons, and the fact that the mean model biases over the SO is most acute in austral summer, our attention here is centered on austral summer (DJF), when the satellite retrievals from MODIS visible channels are deemed most reliable.

\section{a. Assessment of cloud thermodynamic phase products}

To obtain the "best" estimates of liquid-phase cloud properties, the accuracy of cloud phase categorization is vital. This becomes an even greater challenge for the SO where the majority of the observed clouds reside primarily in the temperature range from $0^{\circ}$ to $-30^{\circ} \mathrm{C}$ (Huang et al. 2012a, 2015b). To tackle this issue, it is necessary to perform an intercomparison of the synergistically retrieved cloud phase from different satellite products, whereby the qualities and uncertainties of these products can be better appreciated. This is particularly 
(a)
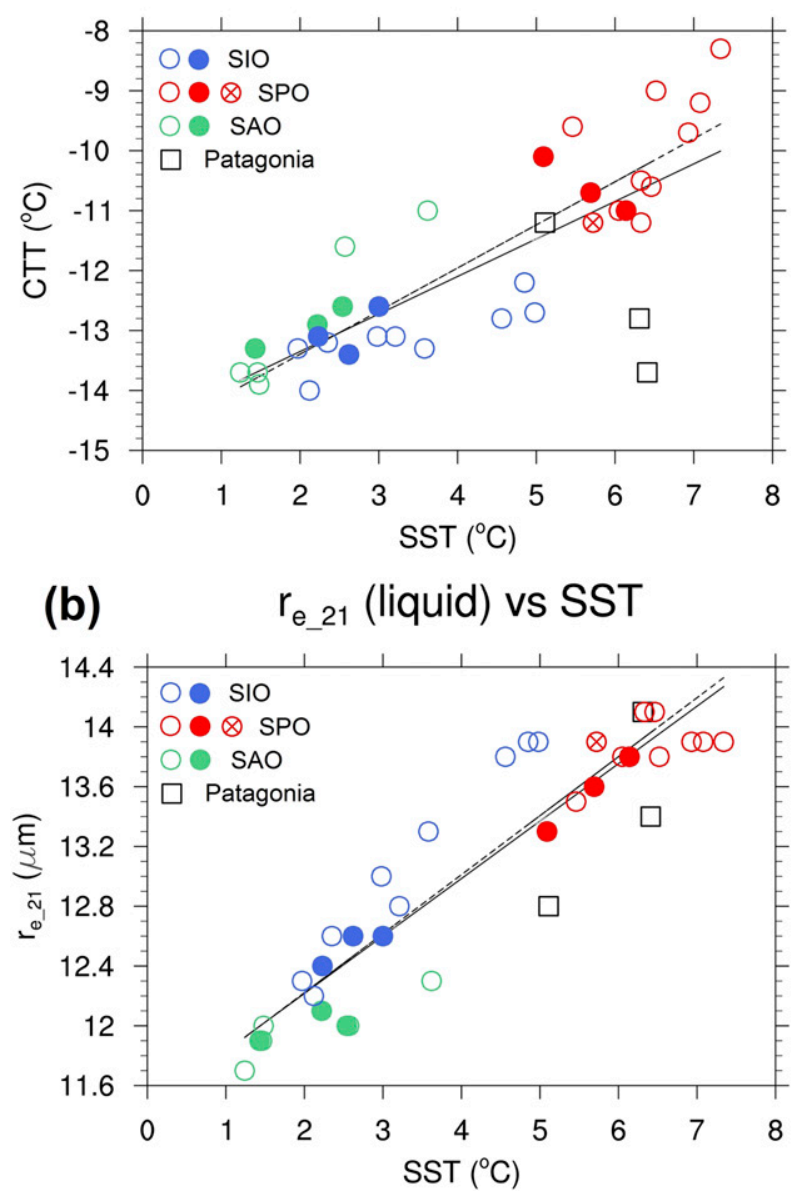

FIG. 2. Box-mean (a) CTTs and (b) $r_{e \_21}$ of liquid-phase clouds (according to MODIS cloud phase optical properties) over the 36 boxes within the SHB as a function of the box-mean SSTs for the 4-yr austral summer. Different sectors are indicated with different color circles as shown in the legends. Filled circles represent the boxes included in the sector-based analysis in section 4. Crossed circles represent the box in which Macquarie Island $\left(54.50^{\circ} \mathrm{S}\right.$, $158.94^{\circ} \mathrm{E}$ ) resides. Black squares represent the three boxes nearest to Patagonia in South America.

important when we use the complementary retrieved variables provided by different sensors.

A comparison of the collocated cloud phase retrievals from the three A-Train products over the merged SO sectors (merged SIO, SPO, and SAO) during 2006-11 DJF (we extended the study period to include 2006 in order to obtain the largest samples possible for the AMCC dataset) is presented in Table 4. Note that all percentages are with respect to absolute occurrence of clouds. Given that the CALIOP dataset is arguably the best available observation for cloud phase, it is used as a baseline in our study, although a more comprehensive global validation is still needed. The principal difference between the MODIS CPOP and CPI products is that the CPOP algorithm is based primarily on the near-infrared and visible bands ratio while the CPI algorithm uses the brightness temperature difference of two thermal infrared bands. According to CALIOP, the SO is found to be covered by liquid-, ice- and uncertain-phase cloud tops $67.5 \%, 30.7 \%$, and $1.9 \%$ of the time in summer, with respect to the cloudy areas. The prevalence of liquid-phase cloud tops is prominent, with the RF increased up to about $70 \%$ over higher latitudes (not shown). It is evident that the MODIS CPOP retrievals agree well with CALIOP, with MODIS CPOP correctly identifying $64.5 \%$ of the $67.5 \%$ identified by CALIOP as liquid clouds and correctly identifying $21.1 \%$ of the $30.7 \%$ identified by CALIOP as ice. We attribute most of the around $10 \%$ area where CALIOP identifies ice and MODIS CPOP identifies water as being primarily due to the high sensitivity of CALIOP in detecting optically tenuous cirrus clouds over warmer liquid clouds, such that CALIOP is returning ice while MODIS CPOP returns liquid (because of the influence of the lower and warmer cloud). This is also supported by the warmer liquid CTTs as seen by MODIS than by CALIPSO. The MODIS CPI product reports too much ice and uncertain phase, most of which is liquid according to CALIOP and CPOP. The CPI product only identifies $35.9 \%$ of the $67.5 \%$ liquidphase cloud reported by CALIOP. This CPI result is not unexpected given the known challenges for the MODIS bispectral infrared method in discriminating thermodynamic phase at CTT between $0^{\circ}$ and $-30^{\circ} \mathrm{C}$ (Platnick et al. 2003; Menzel et al. 2010). The differences between the mean CTTs reported by MODIS and CALIOP products for liquid-phase clouds are relatively small $\left(\sim 2^{\circ} \mathrm{C}\right)$, whereas the discrepancies for ice and uncertain phase are large $\left(>10^{\circ} \mathrm{C}\right)$. In summary, the good agreement between CALIOP and MODIS CPOP liquid phase retrievals supports a further investigation of liquid-phase clouds using the AMCC and AMSR-E-MODIS-only (AM) dataset, while bearing in mind the caveat that about $10 \%$ of the liquid clouds identified by CPOP might actually be ice (according to CALIOP) or multilayer clouds.

\section{b. Analysis of liquid-phase clouds using the AMCC dataset}

In this section, the spatiotemporal collocated liquid cloud properties are examined as a function of SST for the merged SO. In so doing, we intentionally neglect any frontal clouds with glaciation or uncertain phase. Considering the various sources of error imposed by each spaceborne instrument, the following requirements must be met in order to mitigate the biases in our analysis. 
TABLE 4. Comparison of frequencies of occurrence of cloud thermodynamic phase from three A-Train satellite products and associated cloud properties. Frequencies of occurrence of individual cloud thermodynamic phase from three A-Train products as introduced in Table 1. All percentages are with respect to absolute occurrence of clouds during austral summer. The sum of the frequencies is also shown for each phase next to the respective phase name in the left column. CTH and CTT mean values and standard deviations (in parentheses) of the examined cloud properties for each phase are also shown.

\begin{tabular}{|c|c|c|c|}
\hline & Liquid $_{\text {CPOP }}$ & Ice $_{\mathrm{CPOP}}$ & Uncertain $_{\mathrm{CPOP}}$ \\
\hline \multicolumn{4}{|c|}{ CALIPSO top-layer liquid $(67.5 \%)$} \\
\hline & \multicolumn{3}{|c|}{ Frequencies } \\
\hline $\operatorname{Liquid}_{\mathrm{CPI}}(35.9 \%)$ & $35.9 \%$ & $0.0 \%$ & $0.0 \%$ \\
\hline $\operatorname{Ice}_{\mathrm{CPI}}(21.2 \%)$ & $18.4 \%$ & $2.4 \%$ & $0.4 \%$ \\
\hline Uncertain $_{\text {CPI }}(10.4 \%)$ & $10.2 \%$ & $0.1 \%$ & $0.1 \%$ \\
\hline \multirow[t]{2}{*}{ Sum } & $64.5 \%$ & $2.5 \%$ & $0.5 \%$ \\
\hline & \multicolumn{3}{|c|}{ CALIPSO CTH $(\mathrm{km})$} \\
\hline Liquid $_{\mathrm{CPI}}$ & $1.42(0.86)$ & - & - \\
\hline Ice $_{\text {CPI }}$ & $3.64(1.74)$ & $5.44(1.83)$ & $4.83(1.88)$ \\
\hline \multirow[t]{2}{*}{ Uncertain $_{\mathrm{CPI}}$} & $2.42(1.31)$ & $3.97(1.85)$ & $3.38(1.56)$ \\
\hline & \multicolumn{3}{|c|}{ CALIPSO CTT $\left({ }^{\circ} \mathrm{C}\right)$} \\
\hline Liquid $_{\mathrm{CPI}}$ & $-1.73(7.04)$ & - & - \\
\hline Ice $_{\mathrm{CPI}}$ & $-18.30(8.57)$ & $-23.93(10.10)$ & $-22.63(7.88)$ \\
\hline \multirow[t]{2}{*}{ Uncertain $_{\mathrm{CPI}}$} & $-12.48(5.75)$ & $-22.67(6.26)$ & $-19.66(6.46)$ \\
\hline & \multicolumn{3}{|c|}{ MODIS CTT $\left({ }^{\circ} \mathrm{C}\right)$} \\
\hline Liquid $_{\mathrm{CPI}}$ & $-2.26(6.97)$ & - & - \\
\hline Ice $_{\text {CPI }}$ & $-16.60(8.70)$ & $-34.10(10.92)$ & $-19.06(8.25)$ \\
\hline Uncertain $_{\mathrm{CPI}}$ & $-14.33(5.87)$ & $-19.08(6.09)$ & $-16.88(7.31)$ \\
\hline \multicolumn{4}{|c|}{ CALIPSO top-layer ice $(30.7 \%)$} \\
\hline & \multicolumn{3}{|c|}{ Frequencies } \\
\hline $\operatorname{Liquid}_{\mathrm{CPI}}(1.7 \%)$ & $1.7 \%$ & $0.0 \%$ & $0.0 \%$ \\
\hline $\operatorname{Ice}_{C P I}(27.9 \%)$ & $6.3 \%$ & $20.9 \%$ & $0.7 \%$ \\
\hline Uncertain $_{\mathrm{CPI}}(1.1 \%)$ & $0.8 \%$ & $0.2 \%$ & $0.1 \%$ \\
\hline \multirow[t]{2}{*}{ Sum } & $8.8 \%$ & $21.1 \%$ & $0.8 \%$ \\
\hline & \multicolumn{3}{|c|}{ CALIPSO CTH $(\mathrm{km})$} \\
\hline Liquid $_{\mathrm{CPI}}$ & $5.15(3.67)$ & - & - \\
\hline Ice $_{\text {CPI }}$ & $6.93(2.55)$ & $8.98(2.12)$ & $7.12(2.16)$ \\
\hline \multirow{2}{*}{ Uncertain $_{\mathrm{CPI}}$} & $5.25(3.01)$ & $6.83(2.34)$ & $5.89(2.55)$ \\
\hline & \multicolumn{3}{|c|}{ CALIPSO CTT $\left({ }^{\circ} \mathrm{C}\right)$} \\
\hline Liquid $_{\mathrm{CPI}}$ & $-23.87(18.10)$ & - & - \\
\hline Ice $_{\mathrm{CPI}}$ & $-36.41(13.20)$ & $-45.02(9.77)$ & $-36.59(11.55)$ \\
\hline \multirow{2}{*}{ Uncertain $_{\mathrm{CPI}}$} & $-26.32(14.90)$ & $-36.09(9.83)$ & $-31.03(12.18)$ \\
\hline & \multicolumn{3}{|c|}{ MODIS CTT $\left({ }^{\circ} \mathrm{C}\right)$} \\
\hline Liquid $_{\text {CPI }}$ & $-2.29(6.07)$ & - & - \\
\hline Ice $_{\text {CPI }}$ & $-17.32(10.01)$ & $-36.75(10.79)$ & $-21.62(10.61)$ \\
\hline \multirow[t]{3}{*}{ Uncertain $_{\mathrm{CPI}}$} & $-12.90(9.36)$ & $-23.42(12.05)$ & $-14.03(11.79)$ \\
\hline & \multicolumn{2}{|c|}{ CALIPSO top-layer uncertain $(1.9 \%)$} & \\
\hline & \multicolumn{3}{|c|}{ Frequencies } \\
\hline $\operatorname{Liquid}_{\mathrm{CPI}}(0.8 \%)$ & $0.8 \%$ & $0.0 \%$ & $0.0 \%$ \\
\hline $\operatorname{Ice}_{C P I}(0.9 \%)$ & $0.7 \%$ & $0.2 \%$ & $0.0 \%$ \\
\hline Uncertain $_{\mathrm{CPI}}(0.2 \%)$ & $0.2 \%$ & $0.0 \%$ & $0.0 \%$ \\
\hline \multirow[t]{2}{*}{ Sum } & $1.7 \%$ & $0.2 \%$ & $0.0 \%$ \\
\hline & & CALIPSO CTH $(\mathrm{km})$ & \\
\hline Liquid $_{\text {CPI }}$ & $3.19(1.21)$ & - & - \\
\hline Ice $_{\text {CPI }}$ & $5.13(2.14)$ & $6.17(2.82)$ & - \\
\hline Uncertain $_{\mathrm{CPI}}$ & $4.45(2.01)$ & - & - \\
\hline & & CALIPSO CTT $\left({ }^{\circ} \mathrm{C}\right)$ & \\
\hline Liquid $_{\text {CPI }}$ & $-13.47(7.97)$ & - & - \\
\hline Ice $_{\text {CPI }}$ & $-25.43(13.70)$ & $-28.75(11.10)$ & - \\
\hline Uncertain $_{\mathrm{CPI}}$ & $-22.53(15.87)$ & - & - \\
\hline & & MODIS CTT $\left({ }^{\circ} \mathrm{C}\right)$ & \\
\hline Liquid $_{\mathrm{CPI}}$ & $-1.19(6.53)$ & - & - \\
\hline Ice $_{\text {CPI }}$ & $-12.01(7.34)$ & $-29.32(8.92)$ & - \\
\hline Uncertain $_{\mathrm{CPI}}$ & $-11.12(6.67)$ & - & - \\
\hline
\end{tabular}


1) "Liquid" phase is reported by both CALIOP and CPOP. In cases where the classification is ambiguous [this often, but not exclusively, happens when CALIOP signals come from lower layers or deep within a cloud (nearing COT of $\sim 3$ ) are attenuated], the phase is reported as uncertain. Analysis is performed with and without the inclusion of any uncertain-phase layers below the liquid-phase tops, allowing a better estimate of uncertainties.

2) Solar zenith angle $\theta_{0}<65^{\circ}$. GW14 noted that when $\theta_{0}$ is larger than approximately $65^{\circ}-70^{\circ}$, MODIS retrievals of COT and $r_{e}$ become unreliable because of optical artifacts. A more detailed analysis of any potential $\theta_{0}$-induced bias is given in section 6 .

3) Only the overcast (fully cloudy within the $1-\mathrm{km}$ pixel and surrounding 1-km pixels) MODIS cloud pixels are used. Partly cloudy and cloud edge pixels are considered to be poor candidates that are expected to yield retrieval failures and suffer great uncertainties (Wolters et al. 2010; Zeng et al. 2012; Cho et al. 2015).

The generation of precipitation may significantly alter the liquid water content, the shape of the cloud droplet size distribution, and radiative properties (e.g., Comstock et al. 2005; vanZanten and Stevens 2005; Wood et al. 2012; Christensen et al. 2013). Thus, it is necessary to examine "precipitating" and "nonprecipitating" clouds separately. Here, we discuss three different methods for identifying potential occurrence of precipitation. Method $\mathrm{A}$ is the CloudSat method (Haynes and Stephens 2007; Lebsock et al. 2008; Kubar et al. 2009; Cho et al. 2015), in which pixels with maximum column radar reflectivity $\mathrm{dB} Z_{\max }$ larger than $-15 \mathrm{~dB} Z$ are considered to contain precipitating clouds, while nonprecipitating clouds have $-30<\mathrm{dB} Z_{\max }<-15 \mathrm{~dB} Z$. This definition largely excludes the very light drizzle with rain rates less than about $0.02 \mathrm{~mm} \mathrm{day}^{-1}$ (Stephens et al. 2010). However, radar bins within the lowest kilometer above the surface are not used due to the strong interaction of the radar pulse with the surface (Marchand et al. 2008). As such, CloudSat has little skill in detecting any precipitating clouds within the lowest kilometer, leading to a certain portion of detected boundary layer clouds (BLCs) being characterized as nonprecipitating by default. This limitation may be nontrivial over the SO where the bulk of clouds are found to reside primarily in the lowest kilometer year round (Huang et al. 2012a). Method B is the MODIS method, whereby MODIS $r_{e_{-} 21}$ is used as a threshold (i.e., pixels with $r_{e_{-} 21}>14 \mu \mathrm{m}$ are indicative of precipitating clouds with rain rate greater than $\sim 2 \mathrm{~mm} \mathrm{day}^{-1}$ ). This $r_{e \_21}$ threshold has been identified in previous studies for warm marine BLCs, using both satellite observations and model simulations

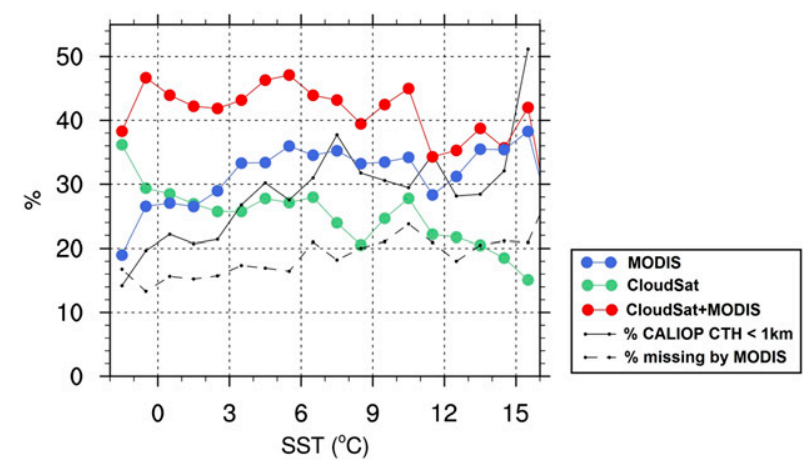

FIG. 3. The 2006-11 summertime precipitation frequencies for liquid-phase clouds as a function of SST. Statistics are derived from the AMCC dataset over the merged SO sectors, using the three methods discussed in section $4 \mathrm{~b}$. Green-filled circles represent the results using the CloudSat method; blue-filled circles represent the results using the MODIS method; and red-filled circles indicate the results using the combined CloudSat-MODIS method. The lines with filled circles show the precipitation frequencies without the inclusion of uncertain phase given by the CALIOP product. The black solid line shows the populations of top-layer CALIOP CTHs within the lowest kilometer. The black dashed line shows the percentages of the liquid-phase clouds detected by CALIOP but missed by MODIS.

(Rosenfeld et al. 2006; Nakajima et al. 2010a,b; Rosenfeld et al. 2012). It should be noted that while the MODIS method does not suffer from any ground clutter contaminations, the exclusion of partly cloudy and cloud edge pixels and failed retrievals, which are often associated with precipitation (e.g., Wang and Feingold 2009; Feingold et al. 2010; Nakajima et al. 2010a; Zhang 2013; Cho et al. 2015), may lead to an underestimate of precipitation frequency and a low bias of $r_{e_{-} 21}$ for precipitating clouds. To partly overcome the limitations of both methods, method C, a combined CloudSat-MODIS method, is also explored. In this method, precipitation is considered to be present if either CloudSat or MODIS reports its occurrence. Note that using a combination of CloudSat and MODIS observations to investigate BLC properties has also been recommended in Christensen et al. (2013), when examining a set of A-Train products.

The summertime frequencies of precipitating liquidphase clouds as a function of SST, reported using the three methods above, are shown in Fig. 3. Considering the limited sampling period and volume of the AMCC dataset as discussed in section 2, only the merged SO sector (a total number of $\sim 342000$ pixels) is examined. As expected, relatively large discrepancies exist between the results. The statistics using the CloudSat method suggest that the mean precipitation frequencies increase from approximately $15 \%$ at around $16^{\circ} \mathrm{C}$ to approximately $35 \%$ at around $0^{\circ} \mathrm{C} \mathrm{SST}$. As discussed above, the low-lying nature of the BLCs over the SO poses a great 
challenge for CloudSat observations, especially at the warmer SSTs, where the frequency of cloud-top heights below $1 \mathrm{~km}$ increases, as observed by CALIOP. The percentage of liquid clouds that is missed by CloudSat increases from approximately $15 \%$ to approximately $50 \%$, when moving from cold to warm SSTs. As a consequence, a considerable amount of the BLCs is categorized as nonprecipitating by CloudSat, particularly over the warmer water. The results with the MODIS method reveal a seemingly opposite trend, with the mean precipitation frequencies decreasing from approximately $35 \%$ at around $16^{\circ} \mathrm{C}$ to below $30 \%$ at around $0^{\circ} \mathrm{C} \mathrm{SST}$. Coincidently, the fraction of missing MODIS retrievals decreases slightly from approximately $25 \%$ to approximately $15 \%$, when moving toward colder water. The mean precipitation frequencies detected using the combined CloudSat-MODIS method are generally higher than that using CloudSat or MODIS alone, varying between approximately $35 \%$ and $45 \%$. A slight increasing tendency toward the colder sea surface is also observed. The inclusion of the CALIOP uncertain phase (not shown) has little impact on the overall frequencies.

Figure 4 displays a range of cloud properties as a function of SST. Corresponding cloud properties with the discrimination between precipitating and nonprecipitating clouds, using the combined CloudSat-MODIS method (method C), are also examined separately. Consistent with the findings in section 3, (MODIS) CTTs of liquid clouds (Figs. 4a-c) display a quasi-linear relationship with the underlying SSTs, with the mean decreasing from about $0^{\circ} \mathrm{C} \mathrm{CTT}$ at $15^{\circ} \mathrm{C} \mathrm{SST}$ to $-10^{\circ} \mathrm{C} \mathrm{CTT}$ at $0^{\circ} \mathrm{C} \mathrm{SST}$. The quartiles suggest that the vast majority (greater than the 75th percentile) of CTTs are below freezing when SST $<$ $4^{\circ} \mathrm{C}$. Using a Student's $t$ test, the trend is found to be statistically significant at a $95 \%$ confidence level regardless of the presence of precipitation, although precipitating clouds tend to have colder cloud tops than nonprecipitating clouds over warmer SSTs.

The mean CTH of the uppermost layer slightly increases toward the colder water (Figs. 4d-f). This general increase of CTH toward colder SSTs is in line with the finding in Kawai et al. (2015), where CALIPSO observations are used to examine CTHs over a number of ocean sectors. CTHs of precipitating clouds are generally higher than that of nonprecipitating clouds. The skewness of the CTH distribution is noteworthy, which suggests that the majority of the liquid-topped clouds are shallow BLCs, but there are sufficient clouds above the boundary layer to increase the mean height noticeably. For this reason, we suggest that the median values are a better indicator of the average state of the clouds. This is also applied to other variables examined below using the AMCC dataset. Over the colder water, the distribution becomes closer to a normal distribution, with the majority of CTHs residing within $1-3.5 \mathrm{~km}$.

COT is a key variable in determining cloud radiative forcing (e.g., Jensen et al. 1994; Kristiansen and Kristjansson 1999). Marchand et al. (2010) discussed the advantages of using MODIS to detect optically thick clouds over oceans. As shown in Figs. $4 \mathrm{~g}-\mathrm{i}$, the median COT increases from about 8 around $15^{\circ} \mathrm{C}$ to 12 around $0^{\circ} \mathrm{C}$. The magnitudes are larger for precipitating clouds (Fig. 4h) but the increasing tendency is driven by the nonprecipitating clouds (Fig. 4i).

The characteristics of LWP resemble that of COT for nonprecipitating clouds, with the overall median and mean values increasing toward the colder water (Figs. $4 \mathrm{j}-1$ ). This result may have further implications for model evaluation. As discussed in previous studies (e.g., Jiang et al. 2012; Komurcu et al. 2014), to date there is virtually no broad consensus in either the spatial structure or the magnitude of liquid and ice water paths between the GCMs, and between GCMs and satellite products.

The value of $r_{e_{2} 21}$ (Figs. $4 \mathrm{~m}-\mathrm{O}$ ), in general, is quite variable across the range of SST, but a decreasing trend toward colder SSTs is also evident, most significant for precipitating clouds (from a median value of $\sim 16 \mu \mathrm{m}$ at $15^{\circ} \mathrm{C}$ to $\sim 14 \mu \mathrm{m}$ at $0^{\circ} \mathrm{C}$; Fig. $\left.4 \mathrm{n}\right)$. The quartiles for precipitating clouds suggest that CloudSat detects a large fraction of very light precipitation with $r_{e_{2} 21}<14 \mu \mathrm{m}$, particularly over the colder water. The reduced droplet size over the colder water may be indicative of a reduction in precipitation intensity (drizzle rate) toward the colder SSTs. While a slight trend in $r_{e_{-} 21}$ is identifiable for nonprecipitating clouds, the change is considerably smaller.

Being derived from $r_{e_{-} 21}, \mathrm{COT}$, and $c_{w}, N_{d}$ does not demonstrate a strong correlation with the underlying SST, albeit the quartiles seem to suggest some relatively large values observed in both the cold and warm range of the SSTs (Fig. 4p). A similar pattern is also noted in McCoy et al. (2015a), who attributed the enhancement to the increased organic mass fraction (at high latitudes) and the increased sulfate aerosols concentration (at low latitudes), using MODIS observations and model simulations. The value of $N_{d}$ for precipitating clouds (Fig. 4q) slightly increases toward the colder water, but the median values are mostly between 30 and $50 \mathrm{~cm}^{-3}$.

Overall, the inclusion of the CALIOP uncertain phase (not shown) slightly increase the magnitudes of CTTs and COT changes across the SSTs, while the impacts on $r_{e_{-} 21}, N_{d}$, and LWP are negligible.

\section{c. Summary of analysis of liquid-phase clouds using the AMCC dataset}

The spatiotemporally collocated AMCC dataset is constructed to study liquid-phase cloud properties as a 

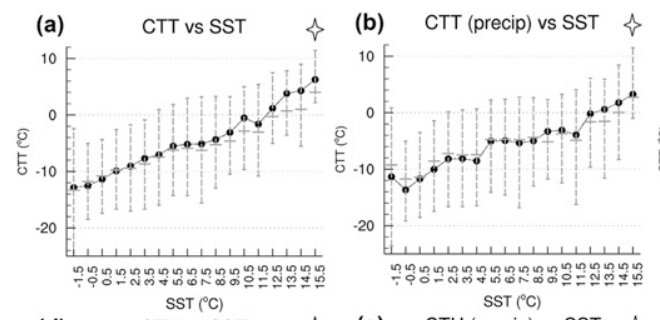

(c) CTT (non-precip) vs SST \&
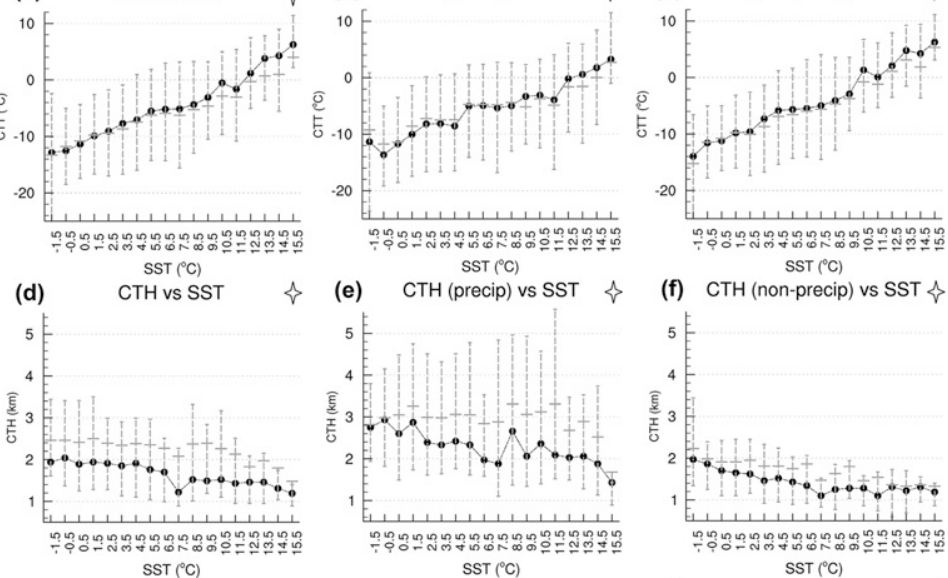

(f) $\mathrm{CTH}$ (non-precip) vs SST $\diamond$
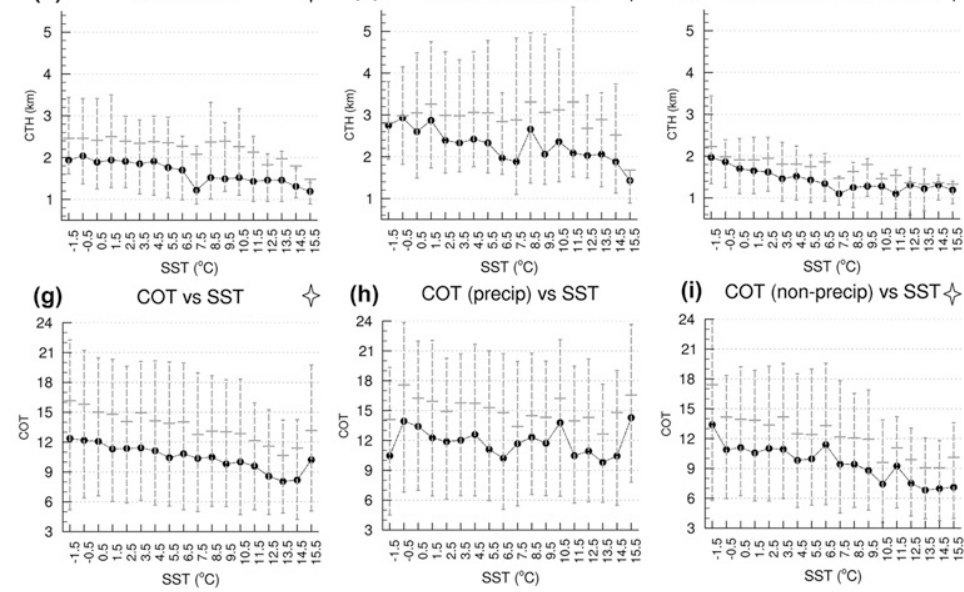

(i) COT (non-precip) vs SST \&
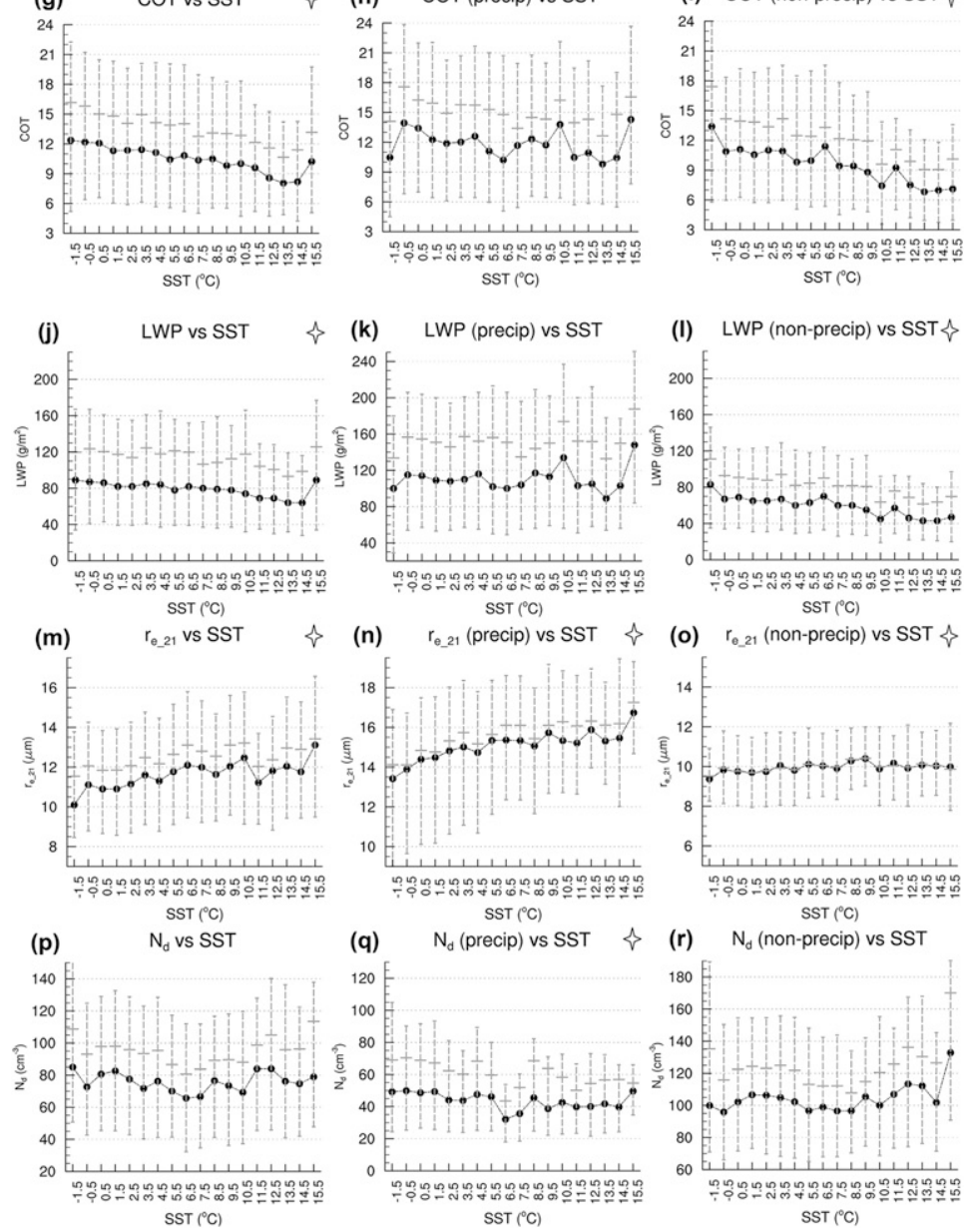

FIG. 4. The 2006-11 summertime cloud properties for liquid-phase clouds derived from the AMCC dataset over the merged SO sectors, as a function of SST, for (left) all clouds, (center) precipitating clouds, and (right) nonprecipitating clouds: (a)-(c) CTT, (d)-(f) CTH, (g)-(i) COT, (j)-(l) LWP, (m)-(o) $r_{e_{-} 21}$, and (p)-(r) $N_{d}$. Lines with dots show the median values without the inclusion of uncertain phase given by the CALIOP product. Long error bars represent the first and the third quartile of all samples for each individual SST bins. Short error bars represent the mean values. Results for SST bins of which the relative frequencies of occurrence less than $0.5 \%$ of integrated population are not shown in the diagrams. Panels marked with a star at the top right indicate the trends in median values are statistically significant at a 95\% confidence level using a Student's $t$ test. 
function of SST over the merged SO regions. A large quantity of SLW is observed, with CTT and $r_{e_{-} 21}$ decreasing toward the cold water. An opposite trend is observed for CTH, COT, and LWP. Notable differences are observed between precipitating and nonprecipitating clouds. In particular, precipitating clouds have fewer but larger drops and greater LWP. The decreasing trend of $r_{e_{-} 21}$ with SST is primarily due to precipitating clouds.

\section{Analysis of liquid-phase clouds using the collocated AMSR-E-MODIS dataset}

In the previous section we have demonstrated the correlation between liquid-phase cloud properties and the underlying SSTs over the merged SO. However, potential differences between the ocean sectors may be embedded in the statistics, which requires further investigation. The AMCC dataset is too sparse for this purpose, and we proceed by using the synergetic AM dataset only. Over $2 \times 10^{9}$ pixels are examined for the merged SO.

Here we only use the MODIS method (method B) for identification of precipitation. While the lack of a constraint obtained by using the CALIOP phase product means larger uncertainties in the MODIS retrievals due to the presence of multilayer clouds and threedimensional (3D) effects (Davis and Marshak 2010), the results in section 4 offer some confidence that these problems are not paramount. Nonetheless, bearing these limitations in mind, in the following work we proceed with care by examining the single-layer clouds only (using the MODIS cloud multilayer flag) (Wind et al. 2010), whereby the retrieval biases are expected to be minimized. Note that because of the different sampled populations, filtering methods, and definitions of precipitation, some differences in the results from the two datasets are expected.

The statistics (Fig. 5) suggest that the precipitation frequencies of liquid-phase clouds vary between sectors, with the lowest frequencies (with respect to the overcast pixels) observed over SAO. The overall mean frequencies decline from approximately $40 \%$ at SSTs greater than $8^{\circ} \mathrm{C}$ to below $20 \%$ at SSTs around $0^{\circ} \mathrm{C}$. As discussed, our sampling method using overcast pixels may lead to an underestimated frequency of precipitating cloud. Indeed, an examination of the partly cloudy pixels (i.e., $1-\mathrm{km}$ pixels identified as likely containing clouds but not surrounded by cloudy pixels) in Fig. 5 indicates that the fraction of partly cloudy pixels increases from approximately $5 \%$ over the cold water to approximately $25 \%$ over the warmer ocean, suggesting that open-cellular shallow cumulus clouds are more

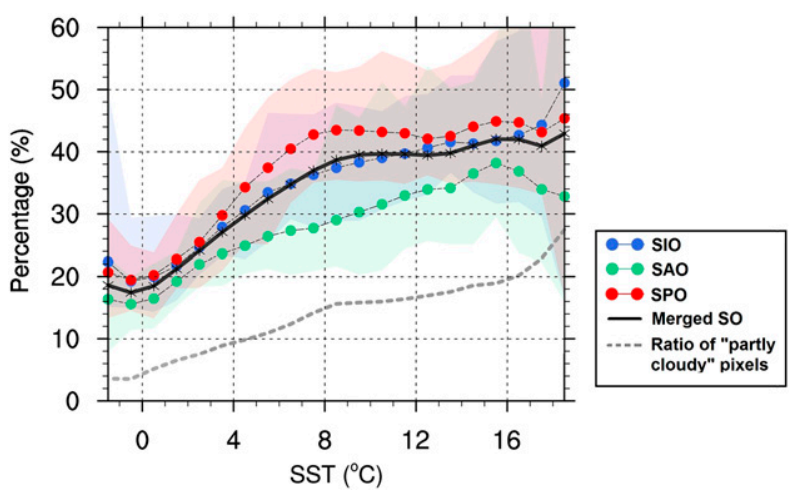

FIG. 5. The 4-yr summertime precipitation frequencies for liquidphase clouds as a function of SST. Statistics are derived from the AM dataset over the three SO sectors, using the MODIS method (method B). The line with blue dots represents SIO sector, the line with red dots represents the SPO sector, and the line with green dots represents SAO sector; the black line represent the mean of the merged SO sectors. The dashed gray line represents the ratio of partly cloudy pixels to overcast pixels. To represent the variability, we use the 36 subsector monthly mean precipitation frequencies from each sector $(3$ summer months $\times 4$ years $\times 3$ subsectors of $10^{\circ}$ ) to derive a coarse probability distribution over individual SST bins. The 10th and 90th percentiles are shown by the corresponding color shading.

prevalent over the warmer SSTs. Accordingly, the precipitating cloud frequencies over the warmer SSTs may even be higher than this estimate. On the other hand, as demonstrated in Fig. 4n, the MODIS method is unable to detect very light precipitation (characterized by smaller particle size) over the colder SSTs. Therefore, the indicated decreasing trend of the precipitation frequencies in Fig. 5 is likely an artifact of the definition. In spite of these limitations and uncertainties, Fig. 5 shows that there are likely significant differences between the sectors (with SAO having a lower occurrence of precipitation or smaller particles) and demonstrates that factors other the SST are important in controlling cloud and precipitation processes.

The statistical liquid-phase cloud properties as a function of SST, examined for the individual SO sectors using the AM dataset, are displayed in Fig. 6. In general, the variables examined preserve many characteristics identified in the composite using the AMCC dataset. Some of these characteristics are even more pronounced. To explore the significance of any intersector differences of the examined variables, we use the 36 subsector monthly mean values from each sector (three summer months multiplied by four years multiplied by three $10^{\circ}$ subsectors) to derive the (coarse) probability distributions for respective variables over individual SST bins. The 10th and 90th percentiles are shown with the shadings. 
(a)

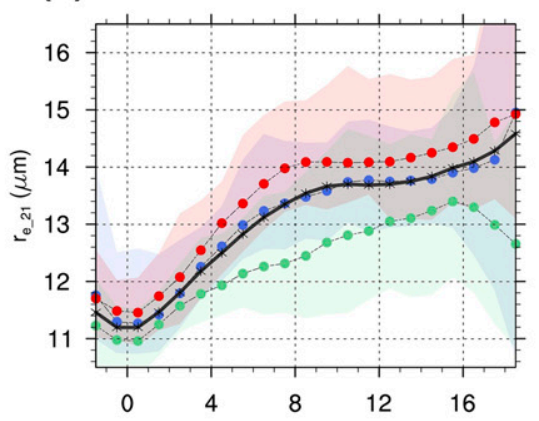

(d)

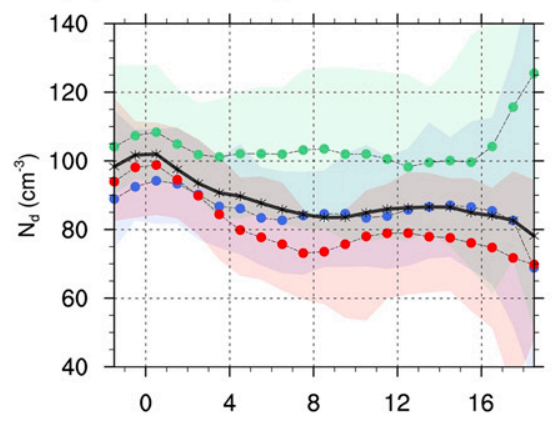

(g) COT vs SST

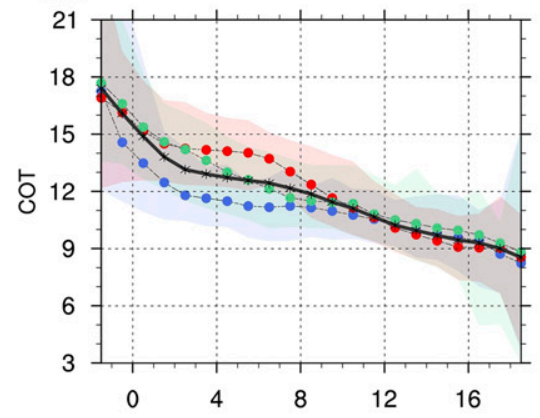

(j)

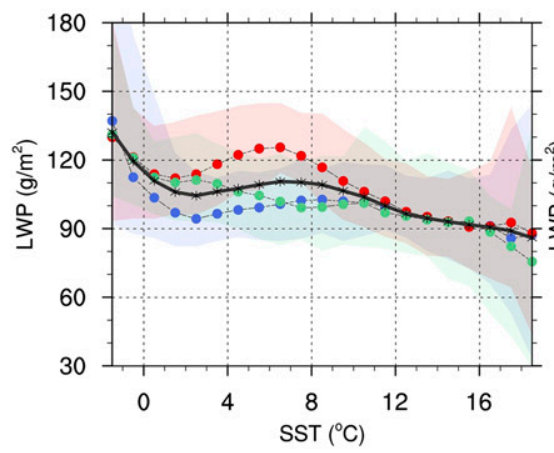

(b) $\quad r_{\text {__21 }}$ (precip) vs SST

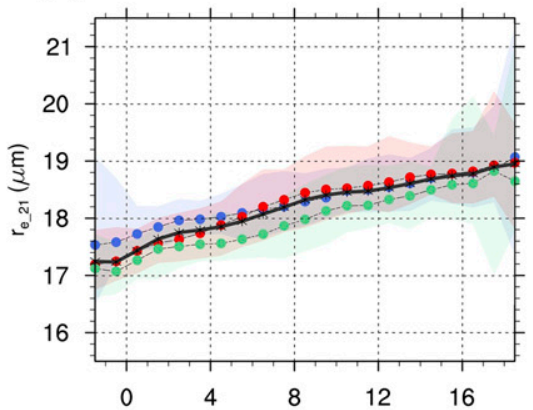

(e) $\quad \mathrm{N}_{\mathrm{d}}$ (precip) vs SST

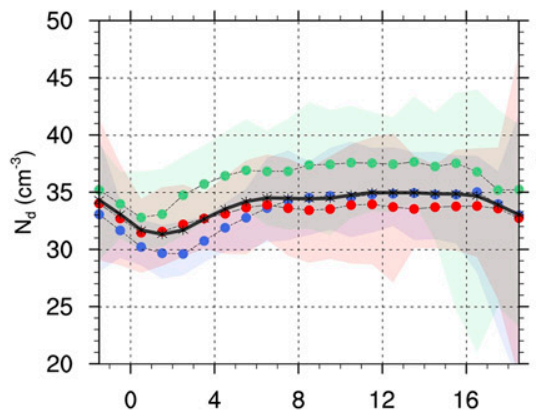

(h) $\quad \mathrm{COT}$ (precip) vs SST

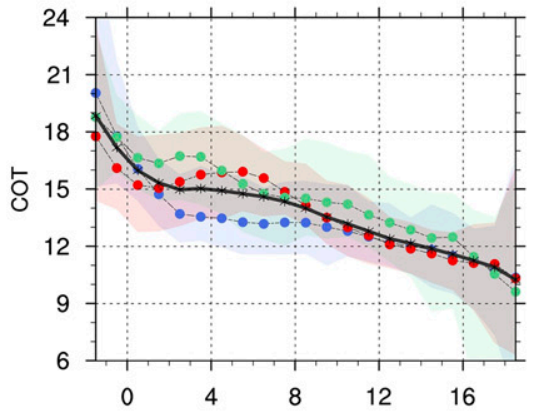

(k) LWP (precip) vs SST

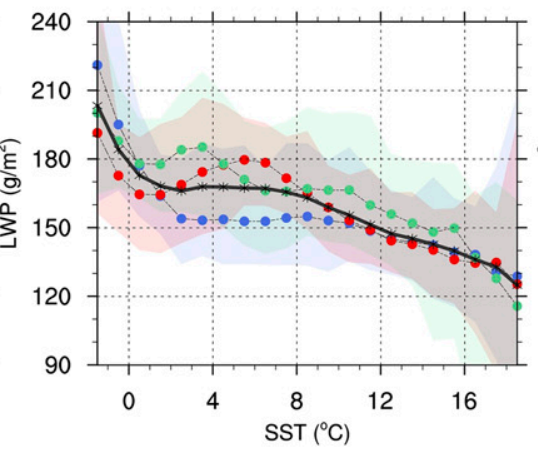

(c) $r_{e_{2} 21}$ (non-precip) vs SST

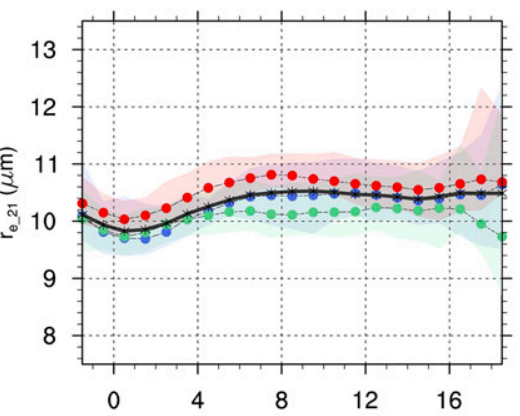

(f) $\quad \mathrm{N}_{\mathrm{d}}$ (non-precip) vs SST

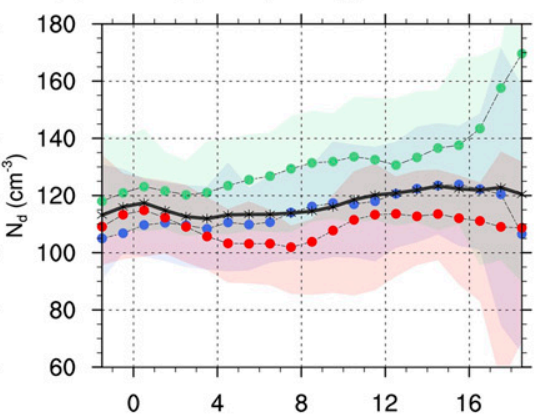

(i) $\mathrm{COT}$ (non-precip) vs SST

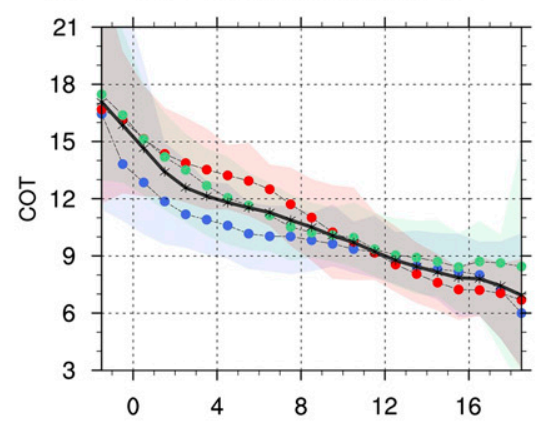

(I) LWP (non-precip) vs SST

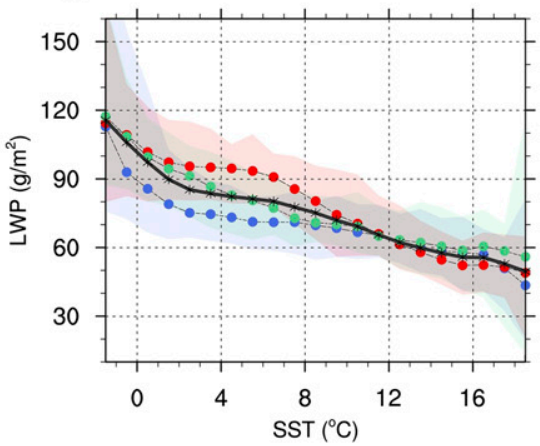

FIG. 6. The 4-yr summertime cloud properties for liquid-phase clouds derived from the collocated AM dataset over the three SO sectors, as a function of SST, for (left) all liquid-phase clouds, and (center) precipitating and (right) nonprecipitating clouds according to MODIS: statistics for (a)-(c) $r_{e_{-} 21}$, (d)-(f) $N_{d}$, (g)-(i) COT, and (j)-(1) LWP. Colors and shadings are for the same sectors as in Fig. 5. Results for SST bins of which the relative frequencies of occurrences less than $0.1 \%$ of the integrated population are not shown in the diagrams. 
Looking first at $r_{e \_21}$ (Figs. 6a-c), the decreasing trend of $r_{e_{-} 21}$ toward colder water is remarkable, although the tendency is nonmonotonic and is most notable over the colder range of $\operatorname{SST}\left(0^{\circ}<\mathrm{SST}<8^{\circ} \mathrm{C}\right)$ and mainly driven by precipitating clouds. A closer examination reveals that intrinsic differences do exist between the three sectors. A "kink" is observed at around $7^{\circ} \mathrm{C}$ for the SIO and SPO sectors, below which $r_{e-21}$ decreases more drastically (down to $\sim 11 \mu \mathrm{m}$ ). The mean $r_{e_{-} 21}$ over SAO is markedly smaller than that over SIO and SPO, most noticeable for SST greater than approximately $4^{\circ} \mathrm{C}$.

As opposed to $r_{e \_21}$, while the mean $N_{d}$ (Figs. 6d-f) appears to increase slightly toward colder water (especially over SST $<4^{\circ} \mathrm{C}$ ), significant sector differences exist. The value of $N_{d}$ over SAO is inherently larger than that over SIO and SPO. There is a sharp increase in $N_{d}$ over SAO toward the very warmest SSTs, with a highly skewed distribution. Note that this feature also appears in Fig. 4r. The enhancement of $N_{d}$ over SAO is largely consistent with that shown in Zeng et al. (2014), where independent measurements of depolarization ratio from CALIOP are also used for the calculations. Previous studies (Kruger and Grassl 2011; McCoy et al. 2015a; Vallina et al. 2006) have attributed this enhancement to the phytoplankton blooms over this region. No obvious trend is observed when looking at precipitating and nonprecipitating clouds separately, other than $N_{d}$ for precipitating clouds being notably smaller than for nonprecipitating clouds.

The statistics of COT (Figs. 6g-i) and LWP (Figs. 6j-1), again, share many similarities and both exhibit a strong correlation with the underlying SST. While this behavior is largely consistent with the AMCC composites, the tendencies here are unequivocally stronger. It should be noted that the sharp increase over SST $<0^{\circ} \mathrm{C}$ is not very obvious in the AMCC composites (Figs. 4j-1). Given that the subfreezing SSTs region is very close to the Antarctic sea ice, the retrievals over this area should be treated with even greater caution.

As CTT is a key parameter for calculating cloud radiative forcing, it is important to appreciate how the cloud characteristics vary with CTT. Here we introduce a set of joint histograms (Fig. 7) in which cloud properties are examined as a function of SST and (MODIS) CTT. To more directly explore how the cloud properties vary as the clouds grow, we also show the join histograms as a function of SST and CTH (see section S2 of the supplementary material). The results are found to be largely consistent. Note that we have merged the three ocean sectors again here to derive a bulk composite for the SO regions.

As shown in the frequency diagrams (Figs. 7a-c), the observed supercooled liquid-phase clouds largely occur in the SST range from $-1^{\circ}$ to $4^{\circ} \mathrm{C}$ and CTT range from $-25^{\circ}$ to $0^{\circ} \mathrm{C}$. The colder water $\left(\mathrm{SST}<\sim 4^{\circ} \mathrm{C}\right.$ ) is dominated by abundant SLW clouds with colder CTTs (down to $-30^{\circ} \mathrm{C}$ ), while CTTs over the warmer SSTs (SST > $\sim 7^{\circ} \mathrm{C}$ ) are substantially warmer. The same characteristics could also be said for the nonprecipitating clouds, although the frequency distribution for precipitating clouds is more dispersed.

An interesting, perhaps surprising, feature in the $r_{e_{-} 21}$ diagram (Figs. $7 \mathrm{~d}-\mathrm{f}$ ) is that droplet size in precipitating clouds is found to decrease monotonically as the SST decreases from $15^{\circ}$ to $0^{\circ} \mathrm{C}$. Droplet size for nonprecipitating clouds does not show an obvious trend with SST. However, over the warmer oceans (SST $>\sim 7^{\circ} \mathrm{C}$ ), $r_{e_{2} 21}$ is larger for lower CTTs (and to a less extent, higher CTHs; see section S2 of the supplementary material) as one might expect for thicker clouds, with a maximum size when $\mathrm{CTT} \approx-10^{\circ} \mathrm{C}$. While over the colder water $\left(\mathrm{SST}<\sim 7^{\circ} \mathrm{C}\right) r_{e_{-} 21}$ is smaller at $\mathrm{CTT} \approx-10^{\circ} \mathrm{C}$ as well as colder cloud tops. This suggests that there exists a supercooled stratocumulus cloud type (potentially associated with markedly smaller $r_{e_{2} 21}$ ) over SST less than approximately $7^{\circ} \mathrm{C}$ while there is generally a lack of this cloud type over warmer SSTs.

The distributions of $N_{d}$ (Figs. 7g-i) display a different pattern from that of $r_{e-21}$, with relatively large values of $N_{d}\left(N_{d}>100 \mathrm{~cm}^{-3}\right)$ being present at CTTs less than approximately $-5^{\circ} \mathrm{C}$ and over SST less than approximately $4^{\circ} \mathrm{C}$. Large values of $N_{d}$ are also found for the warm nonprecipitating clouds (primarily BLCs) over the warm SST range.

As for COT, Figs. 7j-1 show that colder cloud tops are associated with larger COT. The peaks of the COT are observed where the CTTs are colder than approximately $-15^{\circ} \mathrm{C}$, regardless of the presence of precipitation. The vertical gradient, however, appears to be a little more subtle when examined with CTH (section S2 of the supplementary material), which may be attributed to optically thick clouds present at lower SSTs for the lower CTHs (around $2 \mathrm{~km}$; likely stratocumulus) and some higher-altitude clouds (perhaps midlevel cloud associated with frontal systems) that are also optically thick.

Not surprisingly, the pattern of LWP (Figs. 7m-o) resembles that of COT, showing that changes in LWP (rather than $r_{e_{-} 21}$ ) tend to dominate the COT. Also, the maxima within the CTT range from $-10^{\circ}$ to $-20^{\circ} \mathrm{C}$ and SST range between $2^{\circ}$ and $10^{\circ} \mathrm{C}$ are evident.

\section{Uncertainty assessments}

As discussed in section 5, our analysis with the AM dataset is conditioned to single-layer clouds only so that the number of possible spurious retrievals is minimized. 


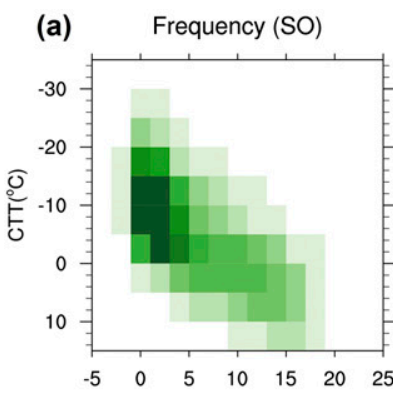

(d) Mean $\mathrm{r}_{\mathrm{e} \_21}(\mathrm{SO})$
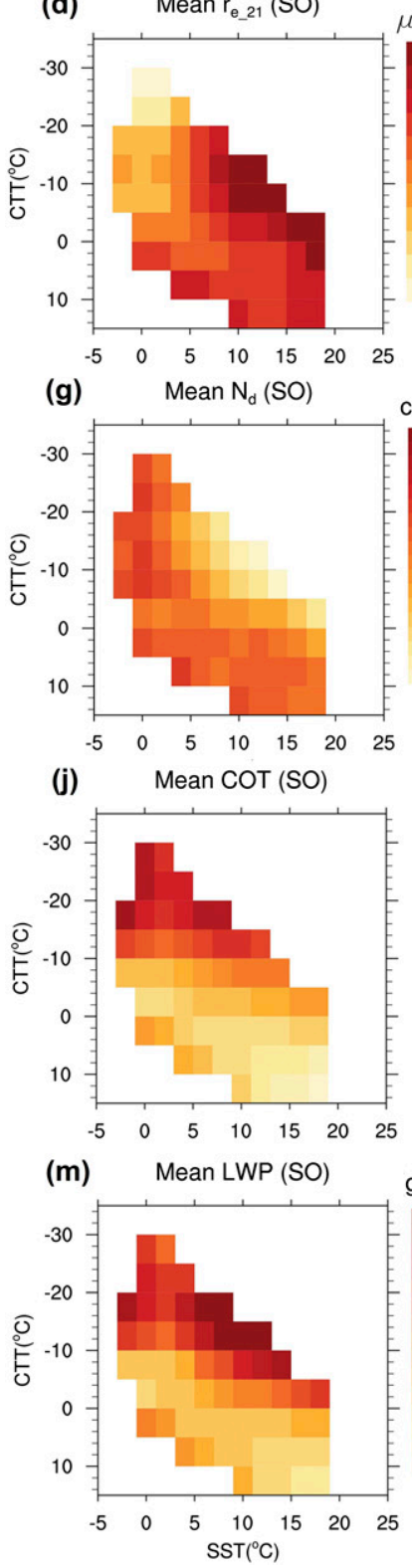

(b) Frequency (SO,precip)

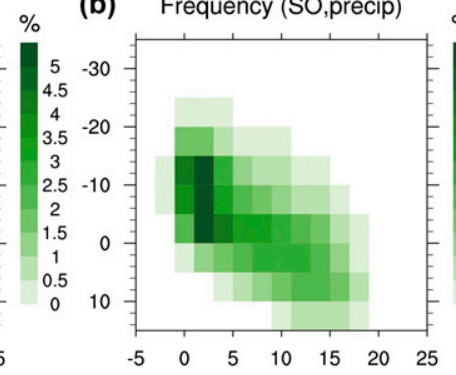

(e) Mean $r_{e \_21}$ (SO,precip)

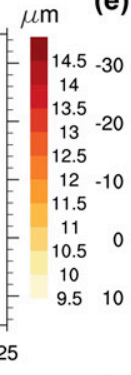

$\mathrm{cm}^{-3} \quad(\mathrm{~h})$

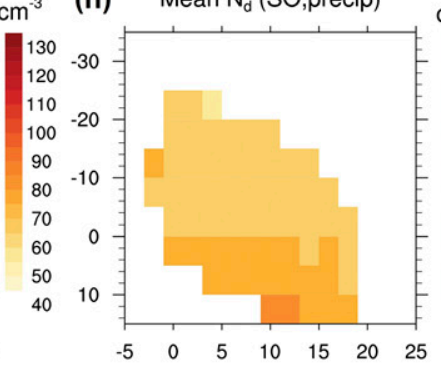

(k) Mean COT (SO,precip)

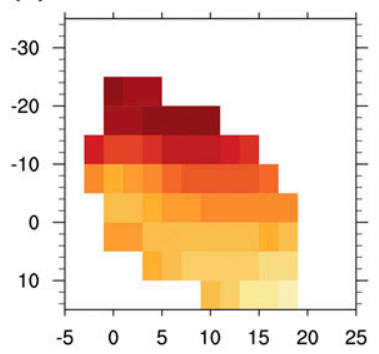

(n) Mean LWP (SO,precip)

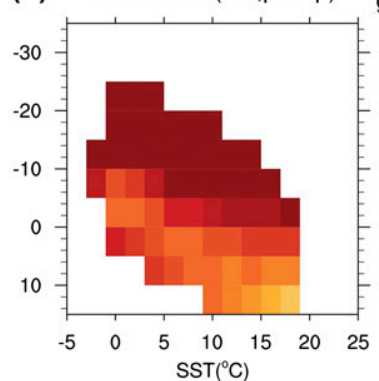

(c) Frequency (SO,non-precip)

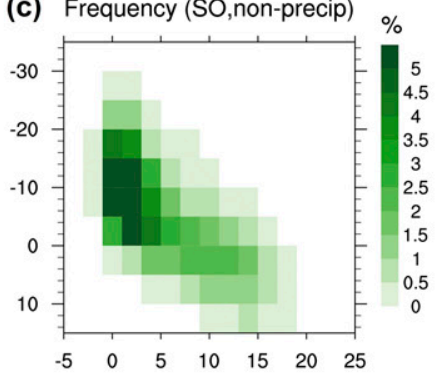

(f) Mean $\mathrm{r}_{\mathrm{e} \_21}$ (SO,non-precip)

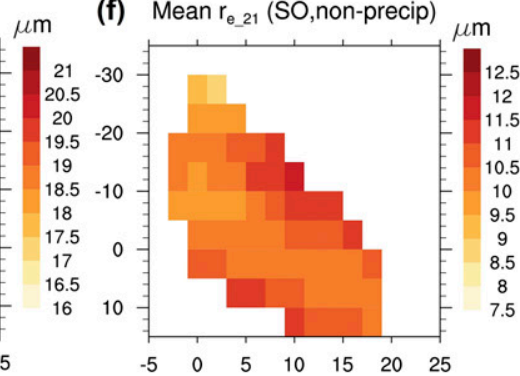

(i) Mean $\mathrm{N}_{d}$ (SO,non-precip)

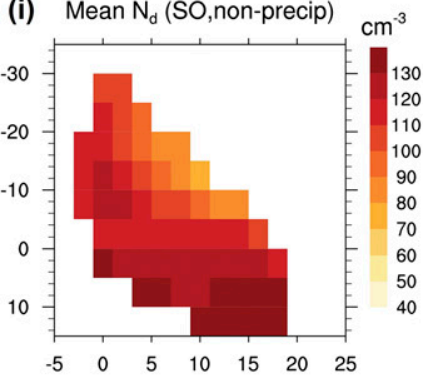

(I) Mean COT (SO,non-precip)

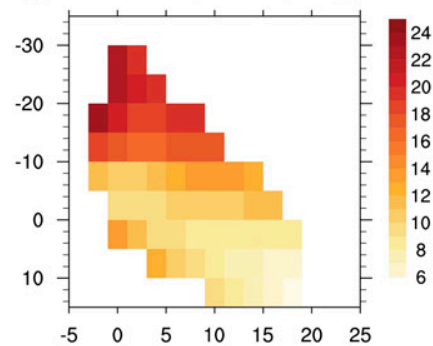

(o) Mean LWP (SO,non-precip) $\mathrm{g} / \mathrm{m}^{2}$

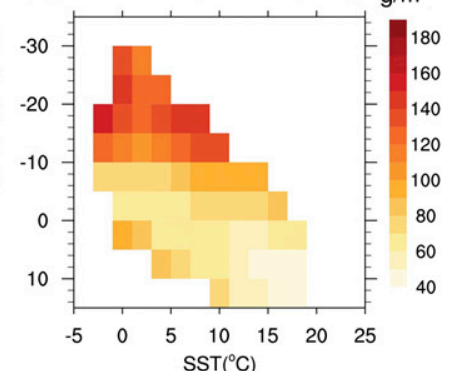

FIG. 7. Joint histograms showing the 4-yr summertime mean cloud properties of liquid-phase clouds over the merged SO sectors, as a function of SST and CTT, using the collocated AM dataset, for (left) all liquid-phase clouds and (center) precipitating and (right) nonprecipitating clouds according to MODIS: (a)-(c) frequencies of occurrence, (d)-(f) mean $r_{e_{-} 21}$, (g)-(i) mean $N_{d}$, (j)-(l) mean COT, and (m)-(o) mean LWP. Relative frequencies of occurrence less than $0.1 \%$ of the integrated population are not shown in the diagrams. 

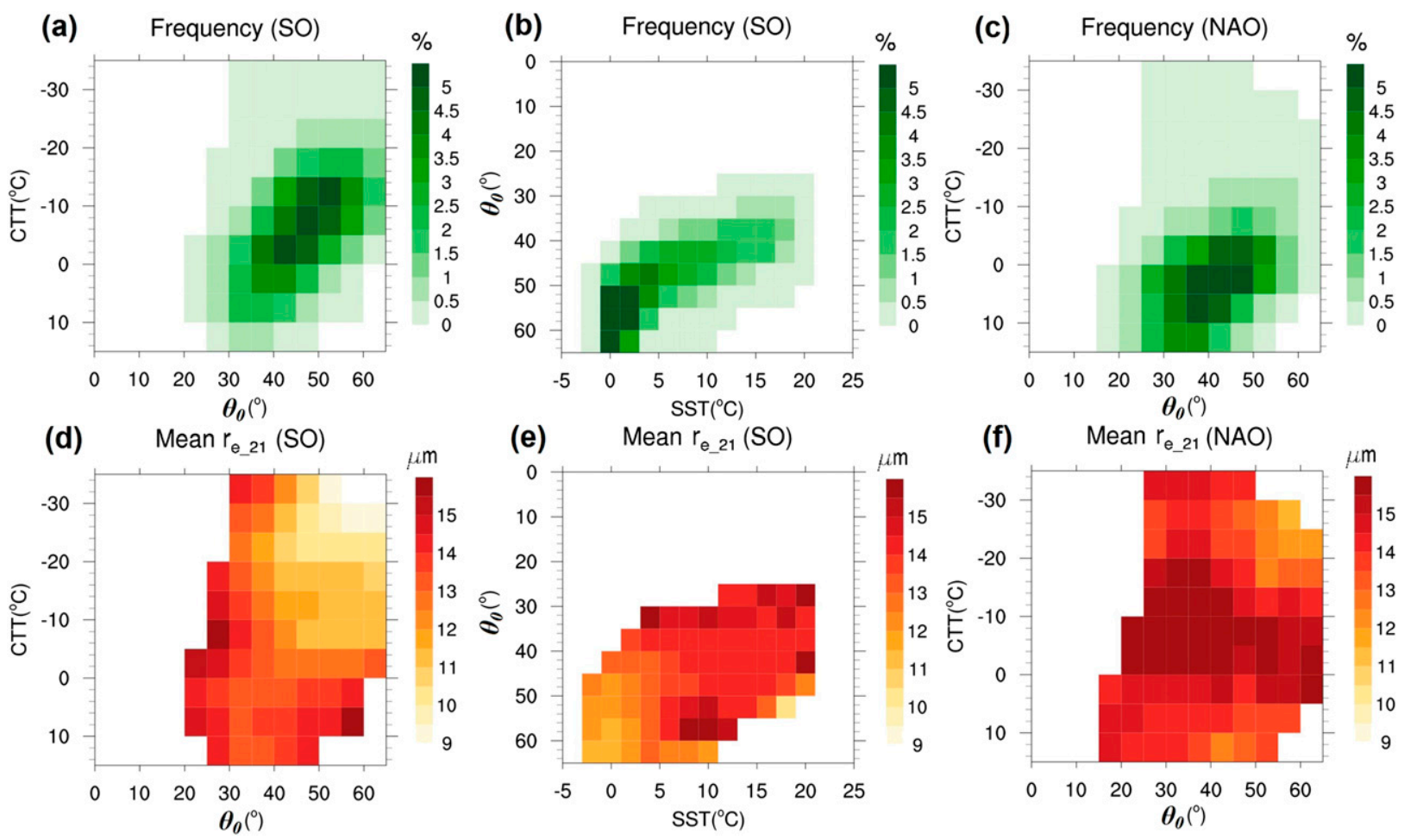

FIG. 8. Joint histograms showing the summertime mean cloud properties of liquid-phase clouds over the merged SO sectors, using the collocated AM dataset. (a) Frequencies of occurrence for the merged SO sectors, as a function of CTT and $\theta_{0}$; (b) frequencies of occurrence for the merged SO sectors, as a function of SST and $\theta_{0}$; (c) frequencies of occurrence for NAO, as a function of CTT and $\theta_{0}$; (d) mean $r_{e-21}$ for the merged SO sectors, as a function of CTT and $\theta_{0}$; (e) mean $r_{e_{21}}$ for the merged SO sectors, as a function of SST and $\theta_{0}$; and (f) mean $r_{e \_21}$ for NAO, as a function of CTT and $\theta_{0}$. Relative frequencies of occurrence less than $0.1 \%$ of the integrated population are not shown in the diagrams.

We also replicate our analysis to examine liquid-phase clouds including the multilayer cloud pixels. Results (not shown) are found to be qualitatively similar, suggesting that any retrieval artifacts due to the complication of the multilayer scenario are not paramount.

Although pixels with solar zenith angle $\theta_{0}>65^{\circ}$ have been excluded in our study, there may still be some biases at lower $\theta_{0}$, according to GW14. To investigate whether the markedly decrease of $r_{e_{2} 21}$ toward colder SSTs could be a retrieval artifact of $\theta_{0}$, more analysis has been performed whereby $r_{e_{-} 21}$ was further aggregated by CTT $-\theta_{0}$ and SST $-\theta_{0}$ pairs, respectively. Our results (Figs. 8d,e) suggest that the decrease of $r_{e_{-} 21}$ with increasing $\theta_{0}$ is only evident for cold cloud tops (CTT $<$ $\sim-5^{\circ} \mathrm{C}$ ) and not for warm cloud tops (CTT $>\sim-5^{\circ} \mathrm{C}$ ). Similarly, the decrease of $r_{e_{\_} 21}$ with increasing $\theta_{0}$ is evident for cold SSTs $\left(\mathrm{SST}<\sim 5^{\circ} \mathrm{C}\right.$ ) but not for warm SSTs (SST $>\sim 5^{\circ} \mathrm{C}$ ). If the decrease of $r_{e \_21}$ was dominated by a retrieval artifact due to the large $\theta_{0}$, one would expect the artifacts to be apparent for all clouds regardless of CTT or SST, which is not the case. This result suggests that $\theta_{0}$ influence (if any) cannot completely explain the observed $r_{e_{2} 21}$ trend. In other words, $r_{e_{2} 21}$ with CTT and SST (or solar zenith angle) is nonlinear and the dependence of $r_{e_{-} 21}$ is not well described using a multiple linear regression. It is most likely that the smaller $r_{e_{-21}}$ (on average) being observed over colder SSTs at larger $\theta_{0}$ is due to the fact that clouds with colder CTTs form preferentially over the colder water (Figs. 8a,b), where $\theta_{0}$ happens to be large, rather than a bias in the retrieval due to large $\theta_{0}$. This is further supported by the strong correlation shown in Fig. $2 \mathrm{~b}$ for the SHB, which is largely independent of $\theta_{0}$ and hence cannot be interpreted as a result of a $\theta_{0}$-induced bias, as well as the fact that nonprecipitating clouds show no trend with SST or $\theta_{0}$ (when using either the AMCC or AM datasets). Therefore, the marked tendency of $r_{e_{-} 21}$ for precipitating clouds appears to be a real physical feature of the clouds examined. For comparison, we repeated the CTT $-\theta_{0}$ pair analysis for NAO (Figs. 8c,f), which covers the same latitude band $\left(40^{\circ}-70^{\circ} \mathrm{N}\right)$ as the SO sectors $\left(40^{\circ}-70^{\circ} \mathrm{S}\right)$. We do not observe a clear trend in $r_{e_{2} 21}$ as a function of CTT and $\theta_{0}$. Nevertheless, our analysis above suggests that the $\theta_{0}$ issue may be more complicated than previously suggested. Further investigations are needed in future dedicated studies to 
more systematically understand its impact on the retrieved variables.

Retrievals of $r_{e}$ derived from different MODIS channels may differ significantly (e.g., Zhang and Platnick 2011; Zhang et al. 2012). To appreciate any potential influence of systematic differences between the retrievals of effective radius on the overall statistics, we also perform the analysis on $r_{e_{-} 37}$ and $r_{e_{-} 16}$ (note that $r_{e_{-} 16}$ retrievals may be less reliable because of the damage in the 1.6- $\mu \mathrm{m}$ channel; Wang et al. 2006). Again, the results (not shown) are qualitatively consistent with that from $r_{e_{-} 21}$. Following Zeng et al. (2014), we also examined the relative difference between $r_{e_{2} 21}$ and $r_{e_{-} 37}$ (see section $\mathrm{S} 3$ in the supplementary material). We found that the mean relative differences for the majority of the clouds (CTTs between $0^{\circ}$ and $-10^{\circ} \mathrm{C}$ ) are relatively small $(<10 \%)$, but larger $3 \mathrm{D}$ effect may be present for shallower and horizontally smaller clouds, which occur preferentially over the warm waters.

A notable limitation of this study that should readily be recognized is that the use of daytime-only observations may lead to potential biases due to any diurnal cycle of cloud properties. Also, daytime retrievals from CALIOP are less reliable than that from nighttime retrievals because of the lower signal-to-noise ratio during the day. These issues are beyond the scope of this paper.

\section{Discussion and concluding remarks}

In this study the unique nature of the Southern Ocean (SO) clouds is examined using four years of summertime spatiotemporal collocated A-Train satellite observations. Key findings are summarized below:

Clouds of all phases:

- The SO is covered by low- and midlevel liquidphase clouds over $50 \%$ of the time, as reported by various satellite products. The liquid-phase clouds observed over the colder ocean are dominated by supercooled liquid water (SLW).

- The examined liquid-phase cloud properties demonstrate a strong correlation with the underlying sea surface temperature (SST), while only weak correlations are observed for ice- and uncertainphase cloud properties.

Liquid-phase clouds only:

- Overall, the cloud-top temperatures (CTTs) and effective radius retrieved from the $2.1-\mu \mathrm{m}$ channel $r_{e_{-} 21}$ are found to be decreasing toward colder SSTs, while the opposite trend is observed for cloud-top height $(\mathrm{CTH})$, cloud optical thickness (COT), and liquid water path (LWP). Cloud droplet number concentration $N_{d}$ is not highly sensitive to SST.
TABLE 5. Properties of nonprecipitating clouds over cold and warm SSTs in the SO, derived from the AMCC dataset (Fig. 4); numbers in parentheses are derived from the collocated AM dataset (Fig. 6). Cloud properties with no statistically significant trends identified in Figs. 4 and 6 are considered to be constant across the range SSTs.

\begin{tabular}{lcc}
\hline \multicolumn{1}{c}{ Property } & Cold SST $\left(0^{\circ} \mathrm{C}\right)$ & Warm SST $\left(15^{\circ} \mathrm{C}\right)$ \\
\hline CTH $(\mathrm{km})$ & 2 & 1.5 \\
CTT $\left({ }^{\circ} \mathrm{C}\right)$ & -10 & 5 \\
COT & $11(14)$ & $7(8)$ \\
LWP $\left(\mathrm{g} \mathrm{m}^{-2}\right)$ & $70(90)$ & $40(50)$ \\
$r_{e_{-} 21}(\mu \mathrm{m})$ & $10(10.5)$ & $10(10.5)$ \\
$N_{d}\left(\mathrm{~cm}^{-3}\right)$ & $105(120)$ & $105(120)$ \\
Mean lapse rate $\left({ }^{\circ} \mathrm{C} \mathrm{km}^{-1}\right)$ & 5 & 6.7 \\
\hline
\end{tabular}

- Notable differences are observed between "nonprecipitating" and "precipitating" clouds. Precipitating clouds have fewer and larger drops, and greater LWP. The decreasing trend of $r_{e_{-} 21}$ with SST is primarily due to precipitating clouds.

- Despite the marked correlations between the liquid-phase cloud properties with SST, notable intersector differences also exist. In particular, the South Atlantic Ocean is generally characterized by smaller $r_{e_{-} 21}$ and larger $N_{d}$.

- Over the warmer oceans (SST $>\sim 7^{\circ} \mathrm{C}$ ), $r_{e_{-} 21}$ is larger for colder CTTs (i.e., higher cloud tops), while over the colder water (SST $\left.<\sim 7^{\circ} \mathrm{C}\right) r_{e \_21}$ remains small with the coldest cloud tops $\left(\sim-25^{\circ} \mathrm{C}\right)$ having the smallest $r_{e_{-} 21}$.

- Detection of precipitation over the SO remains a great challenge using the current spaceborne observations, even with the advanced active remote sensor. Large uncertainties in precipitation properties are associated with the ubiquitous boundary layer clouds (BLCs) within the lowest kilometer of the atmosphere.

The median values for various cloud properties over cold SST $\left(0^{\circ} \mathrm{C}\right)$ and warm SST $\left(15^{\circ} \mathrm{C}\right)$ conditions taken from Figs. 4 and 6 are summarized in Table 5 for nonprecipitating and Table 6 for precipitating clouds. Quantitative differences between the AMCC and AM datasets are apparent, but at least for nonprecipitating cloud these differences are essentially within the uncertainties of the observations. From these observed properties, we can deduce estimates of the mean lapse rate from (SST - CTT)/CTH, and following B07, cloud depth $D$ based on a simple (80\%) adiabatic model is given by

$$
\mathrm{LWP}=\frac{1}{2} c_{w} D^{2},
$$

where, as in Eq. (1), $c_{w}$ is the temperature-dependent condensation rate (in $\mathrm{g} \mathrm{m}^{-4}$ ) and depends only on the temperature (lapse rate). For nonprecipitating clouds, 
TABLE 6. As in Table 5, but for precipitating clouds.

\begin{tabular}{lcc}
\hline \multicolumn{1}{c}{ Property } & Cold SST $\left(0^{\circ} \mathrm{C}\right)$ & Warm SST $\left(15^{\circ} \mathrm{C}\right)$ \\
\hline CTH $(\mathrm{km})$ & 3 & 2 \\
CTT $\left({ }^{\circ} \mathrm{C}\right)$ & -14 & 0 \\
COT & $12(15)$ & $12(11)$ \\
LWP $\left(\mathrm{g} \mathrm{m}^{-2}\right)$ & $120(170)$ & $120(140)$ \\
$r_{e_{-} 21}(\mu \mathrm{m})$ & $14(17)$ & $16(19)$ \\
$N_{d}\left(\mathrm{~cm}^{-3}\right)$ & $50(35)$ & $50(35)$ \\
Mean lapse rate $\left({ }^{\circ} \mathrm{C} \mathrm{km}^{-1}\right)$ & 4.6 & 7.5 \\
\hline
\end{tabular}

the calculated $c_{w}$ over the cold water $\left(\mathrm{SST}=0^{\circ} \mathrm{C}\right)$ is approximately $0.0009 \mathrm{~g} \mathrm{~m}^{-4}$, with an estimated $D$ of approximately $400 \mathrm{~m}$. The calculated $c_{w}$ over the warm water $\left(\mathrm{SST}=15^{\circ} \mathrm{C}\right)$ is approximately $0.002 \mathrm{~g} \mathrm{~m}^{-4}$, with an estimated $D$ of approximately $200 \mathrm{~m}$, thinner than that over the cold water. The median values of LWP (COT) are within a range of $40-90 \mathrm{~g} \mathrm{~m}^{-2}(7-14)$, suggesting that these clouds are most likely to be shallow stratocumulus (e.g., B07; Huang et al. 2015a, which is consistent with visual inspection of satellite imagery. The mean lapse rate over the cold water $\left(5^{\circ} \mathrm{C} \mathrm{km}^{-1}\right)$ is more stable than over the warm water $\left(6.7^{\circ} \mathrm{C} \mathrm{km}^{-1}\right)$, which is also consistent with more extensive stratocumulus over the colder waters. Given the thin nature of the clouds with cloud tops near $2 \mathrm{~km}$, it seems likely that the nonprecipitating cloud layers over the cold water are decoupled (or elevated) from the surface. Thin, elevated cloud layers residing above a decoupled boundary layer were encountered during ACE-1 (Russell et al. 1998) and some recent flights over the high-latitude SO (Chubb et al. 2013, 2016).

Unlike the nonprecipitating case, precipitating clouds are more complicated. The estimates of cloud properties from the AMCC and AM datasets are not always
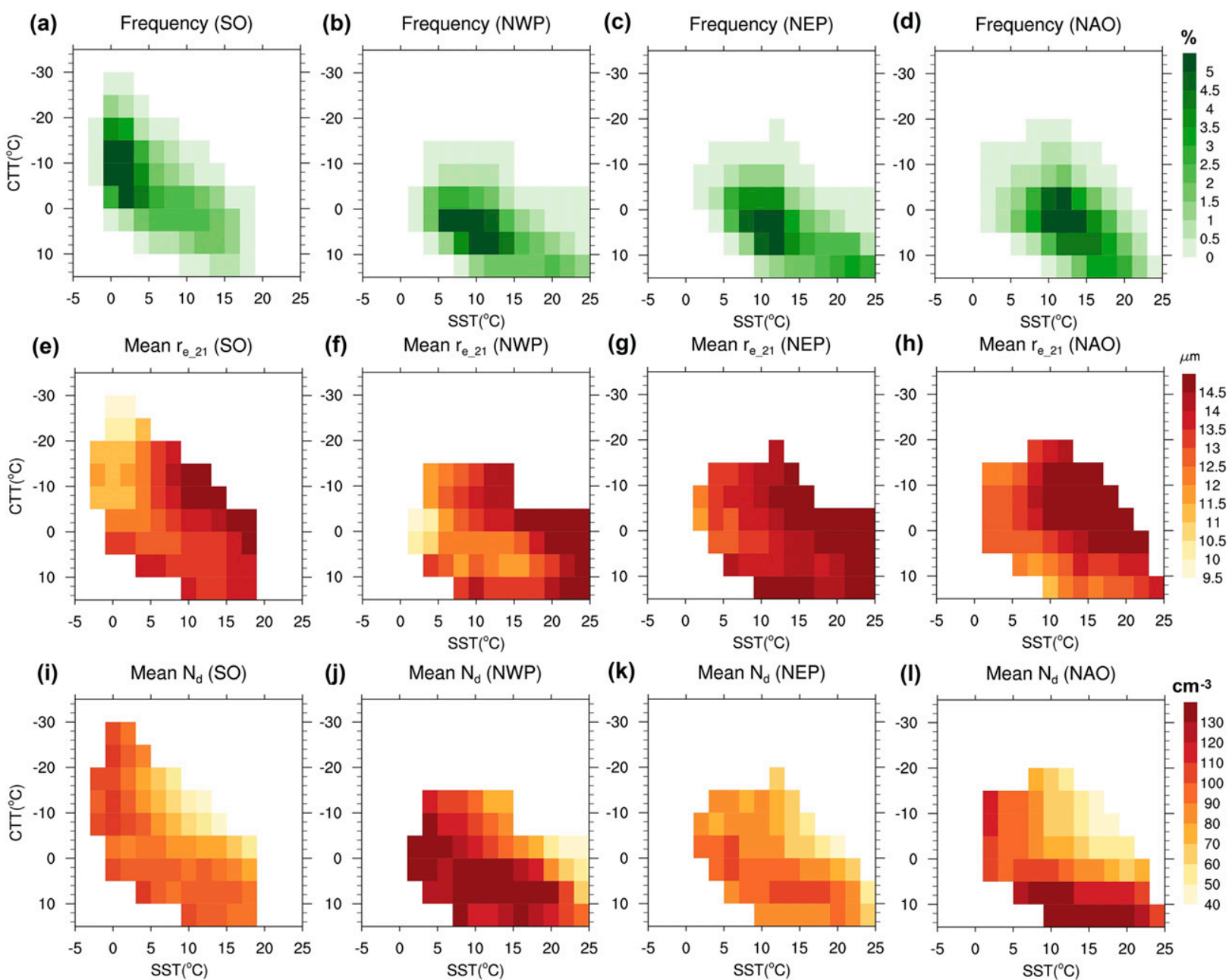

FIG. 9. Joint histograms showing the 4-yr summertime mean cloud properties of all liquid-phase clouds over the merged SO sectors, NWP, NEP, and NAO sectors, as a function of SST and CTT, for (a)-(d) frequencies of occurrences, (e)-(h) statistics for $r_{e \_21}$, and (i)-(1) statistics for $N_{d}$. Relative frequencies of occurrences less than $0.1 \%$ compared to the integrated population are not shown in the diagrams. 
consistent. Also, the simple adiabatic model (and associated assumptions) may be less suitable for deducing the macrophysical properties of these clouds. Nonetheless, we can still see that precipitating clouds have higher cloud tops and are likely physically thicker than nonprecipitating clouds. And as with nonprecipitating cloud, the mean lapse rate of the atmosphere also remains more stable $\left(4.6^{\circ} \mathrm{C} \mathrm{km}^{-1}\right)$ over the cold water than over the warm water $\left(7.5^{\circ} \mathrm{C} \mathrm{km}^{-1}\right)$.

To better appreciate the uniqueness of the SO clouds, in Fig. 9 we show the SST-CTT diagrams for liquid-phase clouds over three midlatitude storm-track regions of the Northern Hemisphere (NH; Fig. 1). The frequency distributions suggest that the majority of the $\mathrm{NH}$ clouds largely fall into the ranges of SST $>4^{\circ} \mathrm{C}$ and CTT $>-5^{\circ} \mathrm{C}$, substantially warmer than that over the SO. The supercooled stratocumulus clouds associated with markedly smaller $r_{e_{-} 21}$ over the cold SSTs is essentially lacking or does not contribute significantly to the overall cloud characteristics in the $\mathrm{NH}$ sectors, although each of the NH sectors displays some regional features. For instance, the northwestern Pacific (NWP) is characterized by the majority of warm BLCs with the largest $N_{d}$, consistent with earlier studies and the regional aerosol characteristics (Chin et al. 2004; Moore et al. 2013). It is also interesting to note that even during the boreal winter, the NH SSTs rarely drop below $4^{\circ} \mathrm{C}$ (Fig. 1b), highlighting the truly unique nature of the atmosphere over the cold SSTs at the high-latitude SO.

Our study has been focused on cloud properties that can be deduced directly from satellite observations. Admittedly, correlation does not mean causality. Atmospheric dynamical processes are central in shaping the cloud and precipitation characteristics over the SO, which needs to be emphasized. In general, the lower-troposphere structure over the SO is not well understood. For example, Kawai et al. (2015) find that the well-established stability indices are unable to explain the cloud-top height tendency of the low clouds over the SO, possibly due to the coarse resolution of reanalysis products not being able to represent the vertical structure. This coincides with the findings in Muhlbauer et al. (2014), who point out that the stability indices are poorly correlated with the mesoscale cloud morphologies over the SO. It is possible that a lack of ice nuclei plays an important role for the prevalence of SLW over the cold SO, as has been suggested by Burrows et al. (2013), among others, and we are not discounting this possibility. The source and variability of cloud condensation nuclei and ice nuclei over the SO remain underexplored (Quinn and Bates 2011; Wilson et al. 2015). Many other key variables, such as cloud-base height, surface flux, and cloud-top entrainment rate, also need to be better observed. Nevertheless, our results do show that the cold SST regions of the SO are associated with unique cloud properties and as such these regions need to be the focus of further study. In situ observations (including cloud and aerosol microphysical properties, as well as thermodynamics) are needed in order to understand the mechanisms involve, and to evaluate the validity of satellite retrievals and associated assumptions upon which this and other studies rely.

Acknowledgments. This work is supported by Australian Research Council Grant LP120100115. The research was directly inspired by the "Workshop on Clouds, Aerosols, Radiation and Air-Sea Interface of the Southern Ocean: Establishing Directions for Future Research" hosted by Prof. Robert Wood at University of Washington in March 2014.

\section{REFERENCES}

Ahmad, I., and Coauthors, 2013: Long-term measurements of cloud droplet concentrations and aerosol-cloud interactions in continental boundary layer clouds. Tellus, 65B, 20138, doi:10.3402/tellusb.v65i0.20138.

Albrecht, B., C. Fairall, D. Thomson, A. B. White, J. B. Snider, and W. H. Schubert, 1990: Surface-based remote sensing of the observed and the adiabatic liquid water content of stratocumulus clouds. Geophys. Res. Lett., 17, 89-92, doi:10.1029/ GL017i001p00089.

Bates, T. S., B. J. Huebert, J. L. Gras, F. B. Griffiths, and P. A. Durkee, 1998: International Global Atmospheric Chemistry (IGAC) Project's First Aerosol Characterization Experiment (ACE 1): Overview. J. Geophys. Res., 103 (D13), $16297-$ 16318, doi:10.1029/97JD03741.

Baum, B. A., W. P. Menzel, R. A. Frey, D. C. Tobin, R. E. Holz, S. A. Ackerman, A. K. Heidinger, and P. Yang, 2012: MODIS cloud-top property refinements for Collection 6. J. Appl. Meteor. Climatol., 51, 1145-1163, doi:10.1175/JAMC-D-11-0203.1.

Bennartz, R., 2007: Global assessment of marine boundary layer cloud droplet number concentration from satellite. J. Geophys. Res., 112, D02201, doi:10.1029/2006JD007547.

Bodas-Salcedo, A., K. D. Williams, P. Field, and A. Lock, 2012: The surface downwelling solar radiation surplus over the Southern Ocean in the Met Office model: The role of midlatitude cyclone clouds. J. Climate, 25, 7467-7486, doi:10.1175/ JCLI-D-11-00702.1.

— , and Coauthors, 2014: Origins of the solar radiation biases over the Southern Ocean in CFMIP2 models. J. Climate, 27, 41-56, doi:10.1175/JCLI-D-13-00169.1.

—, P. G. Hill, K. Furtado, K. D. Williams, P. R. Field, J. C. Manners, P. Hyder, and S. Kato, 2016: Large contribution of supercooled liquid clouds to the solar radiation budget of the Southern Ocean. J. Climate, 29, 4213-4228, doi:10.1175/ JCLI-D-15-0564.1.

Boers, R., J. B. Jensen, and P. B. Krummel, 1998: Microphysical and short-wave radiative structure of marine stratocumulus 
clouds over the Southern Ocean: Summer results and seasonal differences. Quart. J. Roy. Meteor. Soc., 124, 151-168, doi:10.1002/qj.49712454507.

Burrows, S. M., C. Hoose, U. Pöschl, and M. G. Lawrence, 2013: Ice nuclei in marine air: Biogenic particles or dust? Atmos. Chem. Phys., 13, 245-267, doi:10.5194/acp-13-245-2013.

Cesana, G., D. E. Waliser, X. Jiang, and J. L. F. Li, 2015: Multimodel evaluation of cloud phase transition using satellite and reanalysis data. J. Geophys. Res. Atmos., 120, 7871-7892, doi:10.1002/2014JD022932.

Cheng, A., and K.-M. Xu, 2015: Improved low-cloud simulation from the Community Atmosphere Model with an advanced third-order turbulence closure. J. Climate, 28, 5737-5762, doi:10.1175/JCLI-D-14-00776.1.

Chin, M., and Coauthors, 2004: Aerosol distribution in the Northern Hemisphere during ACE-Asia: Results from global model, satellite observations, and sun photometer measurements. J. Geophys. Res., 109, D23S90, doi:10.1029/2004JD004829.

Cho, H.-M., and Coauthors, 2015: Frequency and causes of failed MODIS cloud property retrievals for liquid phase clouds over global oceans. J. Geophys. Res. Atmos., 120, 4132-4154, doi:10.1002/2015JD023161.

Christensen, M. W., G. L. Stephens, and M. D. Lebsock, 2013: Exposing biases in retrieved low cloud properties from CloudSat: A guide for evaluating observations and climate data. J. Geophys. Res. Atmos., 118, 12 120-12 131, doi:10.1002/ 2013JD020224.

Chubb, T. H., J. B. Jensen, S. T. Siems, and M. J. Manton, 2013: In situ observations of supercooled liquid clouds over the Southern Ocean during the HIAPER Pole-to-Pole Observation campaigns. Geophys. Res. Lett., 40, 5280-5285, doi:10.1002/grl.50986.

_ , Y. Huang, J. Jensen, T. Campos, S. Siems, and M. Manton, 2016: Observations of high droplet number concentrations in Southern Ocean boundary layer clouds. Atmos. Chem. Phys., 16, 971-987, doi:10.5194/acp-16-971-2016.

Comstock, K., C. Bretherton, and S. Yuter, 2005: Mesoscale variability and drizzle in southeast Pacific stratocumulus. J. Atmos. Sci., 62, 3792-3807, doi:10.1175/JAS3567.1.

Davis, A., and A. Marshak, 2010: 3D transport of solar radiation in clouds. Rep. Prog. Phys., 73, 026801, doi:10.1088/0034-4885/ 73/2/026801.

Dong, S., S. T. Gille, J. Sprintall, and C. Gentemann, 2006a: Validation of the Advanced Microwave Scanning Radiometer for the Earth Observing System (AMSR-E) sea surface temperature in the Southern Ocean. J. Geophys. Res., 111, C04002, doi:10.1029/2005JC002934.

_ J. Sprintall, and S. T. Gille, 2006b: Location of the Antarctic polar front from AMSR-E satellite sea surface temperature measurements. J. Phys. Oceanogr., 36, 2075-2089, doi:10.1175/JPO2973.1.

Ellis, T. D., T. L'Ecuyer, J. M. Haynes, and G. L. Stephens, 2009: How often does it rain over the global oceans? The perspective from CloudSat. Geophys. Res. Lett., 36, L03815, doi:10.1029/2008GL036728.

Feingold, G., I. Koren, H. Wang, H. Xue, and W. A. Brewer, 2010: Precipitation-generated oscillations in open cellular cloud fields. Nature, 466, 849-852, doi:10.1038/nature09314.

Forbes, R. M., and M. Ahlgrimm, 2014: On the representation of high-latitude boundary layer mixed-phase cloud in the ECMWF global model. Mon. Wea. Rev., 142, 3425-3445, doi:10.1175/MWR-D-13-00325.1.

Franklin, C. N., Z. Sun, D. Bi, M. Dix, H. Yan, and A. BodasSalcedo, 2013: Evaluation of clouds in ACCESS using the satellite simulator package COSP: Global, seasonal and regional cloud properties. J. Geophys. Res. Atmos., 118, 732748, doi:10.1029/2012JD018469.

Frenger, I., N. Gruber, R. Knutti, and M. Münnich, 2013: Imprint of Southern Ocean eddies on winds, clouds and rainfall. Nat. Geosci., 6, 608-612, doi:10.1038/ngeo1863.

Gille, S. T., 2012: Diurnal variability of upper ocean temperatures from microwave satellite measurements and Argo profiles. J. Geophys. Res., 117, C11027, 732-748, doi:10.1029/ 2012JC007883.

Grise, K. M., L. M. Polvani, and J. T. Fasullo, 2015: Reexamining the relationship between climate sensitivity and the Southern Hemisphere radiation budget in CMIP models. J. Climate, 28, 9298-9312, doi:10.1175/JCLI-D-15-0031.1.

Grosvenor, D. P., and R. Wood, 2014: On the effect of solar zenith angle on MODIS cloud optical and microphysical retrievals. Atmos. Chem. Phys., 14, 7291-7321, doi:10.5194/acp-14-7291-2014. T. W. Choularton, T. Lachlan-Cope, M. W. Gallagher, J. Crosier, K. N. Bower, R. S. Ladkin, and J. R. Dorsey, 2012: In-situ aircraft observations of ice concentrations within clouds over the Antarctic Peninsula and Larsen Ice Shelf. Atmos. Chem. Phys., 12, 11 275-11 294, doi:10.5194/acp-12-11275-2012.

Haynes, J. M., and G. L. Stephens, 2007: Tropical oceanic cloudiness and the incidence of precipitation: Early results from CloudSat. Geophys. Res. Lett., 34, L09811, doi:10.1029/ 2007GL029335.

—, C. Jakob, W. B. Rossow, G. Tselioudis, and J. Brown, 2011: Major characteristics of Southern Ocean cloud regimes and their effects on the energy budget. J. Climate, 24, 5061-5080, doi:10.1175/2011JCLI4052.1.

Hoskins, B. J., and K. I. Hodges, 2005: A new perspective on Southern Hemisphere storm tracks. J. Climate, 18, 4108-4129, doi:10.1175/JCLI3570.1.

Hu, Y., and Coauthors, 2009: CALIPSO/CALIOP cloud phase discrimination algorithm. J. Atmos. Oceanic Technol., 26, 2293-2309, doi:10.1175/2009JTECHA1280.1.

- S. Rodier, K. Xu, W. Sun, J. Huang, B. Lin, P. Zhai, and D. Josset, 2010: Occurrence, liquid water content, and fraction of supercooled water clouds from combined CALIOP/IIR/ MODIS measurements. J. Geophys. Res., 115, D00H34, doi:10.1029/2009JD012384.

Huang, Y., S. T. Siems, M. J. Manton, L. B. Hande, and J. M. Haynes, 2012a: The structure of low-altitude clouds over the Southern Ocean as seen by CloudSat. J. Climate, 25, 25352546, doi:10.1175/JCLI-D-11-00131.1.

,,,--- A. Protat, and J. Delanoë, 2012b: A study on the low-altitude clouds over the Southern Ocean using the DARDAR-MASK. J. Geophys. Res., 117, D18204, doi:10.1029/2012JD017800.

, C. Franklin, S. T. Siems, M. J. Manton, T. Chubb, A. Lock, S. Alexander, and A. Klekociuk, 2015a: Evaluation of boundary layer cloud forecasts over the Southern Ocean in a limited-area numerical weather prediction system using in-situ, space-borne and ground-based observations. Quart. J. Roy. Meteor. Soc., 141, 2259-2276, doi:10.1002/qj.2519.

— A. Protat, S. T. Siems, and M. J. Manton, 2015b: A-Train observations of maritime mid-latitude storm-track cloud systems: Comparing the Southern Ocean against the North Atlantic. J. Climate, 28, 1920-1939, doi:10.1175/JCLI-D-14-00169.1.

Im, E., S. L. Durden, and C. Wu, 2006: Cloud profiling radar for the CloudSat mission. Proc. 2005 IEEE Int. Radar Conf., Arlington, VA, Institute of Electrical and Electronics Engineers, 483-486, doi:10.1109/RADAR.2005.1435874. 
Inatsu, M., and B. J. Hoskins, 2004: The zonal asymmetry of the Southern Hemisphere winter storm track. J. Climate, 17, 4882 4892, doi:10.1175/JCLI-3232.1.

Jensen, E. J., S. Kinne, and O. B. Toon, 1994: Tropical cirrus cloud radiative forcing: Sensitivity studies. Geophys. Res. Lett., 21, 2023-2026, doi:10.1029/94GL01358.

Jiang, J. H., and Coauthors, 2012: Evaluation of cloud and water vapor simulations in CMIP5 climate models using NASA "A-Train" satellite observations. J. Geophys. Res., 117, D14105, doi:10.1029/2011JD017237.

Kanitz, T., P. Seifert, A. Ansmann, R. Engelmann, D. Althausen, C. Casiccia, and E. G. Rohwer, 2011: Contrasting the impact of aerosols at northern and southern midlatitudes on heterogeneous ice formation. Geophys. Res. Lett., 38, L17802, doi:10.1029/2011GL048532.

Kawai, H., S. Yabu, Y. Hagihara, T. Koshiro, and H. Okamoto, 2015: Characteristics of the cloud top heights of marine boundary layer clouds and the frequency of marine fog over mid-latitudes. J. Meteor. Soc. Japan, 93, 613-628, doi:10.2151/ jmsj.2015-045.

Komurcu, M., and Coauthors, 2014: Intercomparison of the cloud water phase among global climate models. J. Geophys. Res., 119, 3372-3400, doi:10.1002/2013JD021119.

Kristiansen, J., and J. E. Kristjansson, 1999: Shortwave cloud forcing of marine stratocumulus clouds. Phys. Chem. Earth, 24B, 225-230, doi:10.1016/S1464-1909(98)00042-2.

Kruger, O., and H. Grassl, 2011: Southern Ocean phytoplankton increases cloud albedo and reduces precipitation. Geophys. Res. Lett., 38, L08809, doi:10.1029/2011GL047116.

Kubar, T. L., D. L. Hartmann, and R. Wood, 2009: Understanding the importance of microphysics and macrophysics for warm rain in marine low clouds. Part I: Satellite observations. J. Atmos. Sci., 66, 2953-2972, doi:10.1175/2009JAS3071.1.

Lebsock, M. D., G. L. Stephens, and C. Kummerow, 2008: Multisensor satellite observations of aerosol effects on warm clouds. J. Geophys. Res., 113, D15205, doi:10.1029/2008JD009876.

Liu, Z., and Coauthors, 2009: The CALIPSO lidar cloud and aerosol discrimination: Version 2 algorithm and initial assessment of performance. J. Atmos. Oceanic Technol., 26, 1198-1213, doi:10.1175/2009JTECHA1229.1.

Luo, S., Z. Sun, X. Zheng, and Coauthors, 2015: Evaluation of ACCESS model cloud properties over the Southern Ocean area using multiple-satellite products. Quart. J. Roy. Meteor. Soc., 142, 160-171, doi:10.1002/qj.2641.

Mace, G. G., 2010: Cloud properties and radiative forcing over the maritime storm tracks of the Southern Ocean and North Atlantic derived from A-Train. J. Geophys. Res., 115, D10201, doi:10.1029/2009JD012517.

Marchand, R., G. G. Mace, T. Ackerman, and G. Stephens, 2008: Hydrometeor detection using CloudSat-An Earth orbiting 94-GHz cloud radar. J. Atmos. Oceanic Technol., 25, 519-533, doi:10.1175/2007JTECHA1006.1.

— T. Ackerman, M. Smyth, and W. B. Rossow, 2010: A review of cloud top height and optical depth histograms from MISR, ISCCP, and MODIS. J. Geophys. Res., 115, D16206, doi:10.1029/2009JD013422.

Marchant, B., S. Platnick, K. Meyer, G. T. Arnold, and J. Riedi4, 2016: MODIS Collection 6 shortwave-derived cloud phase classification algorithm and comparisons with CALIOP. Atmos. Meas. Tech., 9, 1587-1599, doi:10.5194/amt-9-1587-2016.

Mason, S., J. K. Fletcher, J. M. Haynes, C. Franklin, A. Protat, and C. Jakob, 2015: A hybrid cloud regime methodology used to evaluate Southern Ocean cloud and shortwave radiation errors in ACCESS. J. Climate, 28, 6001-6018, doi:10.1175/JCLI-D-14-00846.1.

McCoy, D. T., D. L. Hartmann, and D. P. Grosvenor, 2014a: Observed Southern Ocean cloud properties and shortwave reflection. Part I: Calculation of SW flux from observed cloud properties. J. Climate, 27, 8836-8857, doi:10.1175/ JCLI-D-14-00287.1.

,$- \ldots$, and $-2014 \mathrm{~b}$ : Observed Southern Ocean cloud properties and shortwave reflection. Part II: Phase changes and low cloud feedback. J. Climate, 27, 8858-8868, doi:10.1175/JCLI-D-14-00288.1.

, S. M. Burrows, R. Wood, D. P. Grosvenor, S. M. Elliott, P.-L. Ma, P. J. Rasch, and D. L. Hartmann, 2015a: Natural aerosols explain seasonal and spatial patterns of Southern Ocean cloud albedo. Sci. $A d v$., 1, e1500157, doi:10.1126/sciadv.1500157.

—, D. L. Hartmann, M. D. Zelinka, P. Ceppi, and D. P. Grosvenor, 2015b: Mixed-phase cloud physics and Southern Ocean cloud feedback in climate models. J. Geophys. Res. Atmos., 120, 9539-9554, doi:10.1002/2015JD023603.

Menzel, W. P., R. A. Frey, and B. A. Baum, 2010: Cloud top properties and cloud phase algorithm theoretical basis document. NASA Goddard Space Flight Center Rep. ATBDMOD-04, $62 \mathrm{pp}$.

Minobe, S., A. Kuwano-Yoshida, N. Komori, S.-P. Xie, and R. J. Small, 2008: Influence of the Gulf Stream on the troposphere. Nature, 452, 206-209, doi:10.1038/nature06690.

Moore, J. K., M. R. Abbott, and J. G. Richman, 1999: Location and dynamics of the Antarctic polar front from satellite sea surface temperature data. J. Geophys. Res., 104, 3059-3073, doi:10.1029/1998JC900032.

Moore, R. H., V. A. Karydis, S. L. Capps, T. L. Lathem, and A. Nenes, 2013: Droplet number uncertainties associated with CCN: An assessment using observations and a global model adjoint. Atmos. Chem. Phys., 13, 4235-4251, doi:10.5194/ acp-13-4235-2013.

Morrison, A. E., S. T. Siems, and M. J. Manton, 2011: A cloud-top phase climatology of Southern Ocean clouds. J. Climate, 24, 2405-2418, doi:10.1175/2010JCLI3842.1.

Muhlbauer, A., I. L. McCoy, and R. Wood, 2014: Climatology of stratocumulus cloud morphologies: Microphysical properties and radiative effects. Atmos. Chem. Phys., 14, 6695-6716, doi:10.5194/acp-14-6695-2014.

Mulcahy, J. P., D. N. Walters, N. Bellouin, and S. F. Milton, 2014: Impacts of increasing the aerosol complexity in the Met Office global numerical weather prediction model. Atmos. Chem Phys., 14, 4749-4778, doi:10.5194/acp-14-4749-2014.

Nakajima, T., K. Suzuki, and G. Stephens, 2010a: Droplet growth in warm water clouds observed by the A-Train. Part I: Sensitivity analysis of the MODIS-derived cloud droplet sizes. J. Atmos. Sci., 67, 1884-1896, doi:10.1175/2009JAS3280.1.

,-- , and,$- 2010 \mathrm{~b}$ : Droplet growth in warm water clouds observed by the A-Train. Part II: A multi-sensor view. J. Atmos. Sci., 67, 1897-1907, doi:10.1175/2010JAS3276.1.

National Science Foundation, 2014: NSF Advisory Committee for Geosciences: Dynamic Earth: GEO Imperatives and Frontiers 2015-2020. National Science Foundation, 33 pp. [Available online at https://www.nsf.gov/geo/acgeo/geovision/start.jsp.]

Naud, C. M., J. F. Booth, and A. D. Del Genio, 2014: Evaluation of ERA-Interim and MERRA cloudiness in the Southern Ocean. J. Climate, 27, 2109-2124, doi:10.1175/ JCLI-D-13-00432.1.

Park, K.-A., P. C. Cornillon, and D. L. Codiga, 2006: Modification of surface winds near ocean fronts: Effects of Gulf 
Stream rings on scatterometer (QuikSCAT, NSCAT) wind observations. J. Geophys. Res., 111, C03021, doi:10.1029/ 2005JC003016.

Platnick, S., M. D. King, S. A. Ackerman, W. P. Menzel, B. A. Baum, J. C. Riedi, and R. A. Frey, 2003: The MODIS cloud products: Algorithms and examples from Terra. IEEE Trans. Geosci. Remote Sens., 41, 459-473, doi:10.1109/ TGRS.2002.808301.

—_, and Coauthors, 2014: MODIS Cloud Optical Properties: User Guide for the Collection 6 Level-2 MOD06/MYD06 product and associated level-3 datasets. NASA Goddard Space Flight Center, $140 \mathrm{pp}$. [Available online at http:/ modis-atmos.gsfc.nasa.gov/_docs/C6MOD06OPUserGuide.pdf.]

Powell, K., and Coauthors, 2010: The CALIOP 532-nm channel daytime calibration: Version 3 algorithm. Proc. 25th Int. Laser Radar Conf., St. Petersburg, Russia, Intl. Radiation Commission, 1367-1370.

Protat, A., S. A. Young, L. Rikus, and M. Whimpey, 2014: Evaluation of hydrometeor frequency of occurrence in a limitedarea numerical weather prediction system using near real-time CloudSat-CALIPSO observations. Quart. J. Roy. Meteor. Soc., 140, 2430-2443, doi:10.1002/qj.2308.

Quinn, P. K., and T. S. Bates, 2011: The case against climate regulation via oceanic phytoplankton sulfur emissions. Nature, 480, 51-56, doi:10.1038/nature10580.

Rosenfeld, D., Y. J. Kaufman, and I. Koren, 2006: Switching cloud cover and dynamical regimes from open to closed Benard cells in response to the suppression of precipitation by aerosols. Atmos. Chem. Phys., 6, 2503-2511, doi:10.5194/ acp-6-2503-2006.

- H. Hang, and P. J. Rasch, 2012: The roles of cloud drop effective radius and LWP in determining rain properties in marine stratocumulus. Geophys. Res. Lett., 39, L13801, doi:10.1029/2012GL052028.

Russell, L., D. H. Lenschow, K. K. Laursen, P. B. Krummel, S. T. Siems, A. R. Bandy, D. C. Thornton, and T. S. Bates, 1998: Bidirectional mixing in an ACE-1 marine boundary layer overlain by a second turbulent layer. J. Geophys. Res., 103, 16411-16 432, doi:10.1029/97JD03437.

Small, J. R., R. A. Tomas, and F. O. Bryan, 2014: Storm track response to ocean fronts in a global high-resolution climate model. Climate Dyn., 43, 805-828, doi:10.1007/ s00382-013-1980-9.

Stephens, G. L., and Coauthors, 2002: The CloudSat mission and the A-Train: A new dimension of space-based observations of clouds and precipitation. Bull. Amer. Meteor. Soc., 83, 17711790, doi:10.1175/BAMS-83-12-1771.

— , and Coauthors, 2010: Dreary state of precipitation in global models. J. Geophys. Res., 115, D24211, doi:10.1029/ 2010JD014532.

Trenberth, K. E., and J. T. Fasullo, 2010: Simulation of present-day and twenty-first-century energy budgets of the Southern Oceans. J. Climate, 23, 440-454, doi:10.1175/2009JCLI3152.1.

Vallina, S. M., R. Simo, and S. Gasso, 2006: What controls CCN seasonality in the Southern Ocean? A statistical analysis based on satellite-derived chlorophyll and $\mathrm{CCN}$ and modelestimated $\mathrm{OH}$ radical and rainfall. Global Biogeochem. Cycles, 20, GB1014, doi:10.1029/2005GB002597.

vanZanten, M., and B. Stevens, 2005: Observations of the structure of heavily precipitating marine stratocumulus. J. Atmos. Sci., 62, 4327-4342, doi:10.1175/JAS3611.1.

Villas Bôas, A. B., O. T. Sato, A. Chaigneau, and G. P. Castelão, 2015: The signature of mesoscale eddies on the air-sea turbulent heat fluxes in the South Atlantic Ocean. Geophys. Res. Lett., 42, 1856-1862, doi:10.1002/2015GL063105.

Walters, D. N., K. D. Williams, I. A. Boutle, and Coauthors, 2014: The Met Office Unified Model Global Atmosphere 4.0 and JULES Global Land 4.0 configuration. Geosci. Model Dev., 7, 361-386, doi:10.5194/gmd-7-361-2014.

Wang, H., and G. Feingold, 2009: Modeling mesoscale cellular structures and drizzle in marine stratocumulus. Part I: Impact of drizzle on the formation and evolution of open cells. J. Atmos. Sci., 66, 3237-3256, doi:10.1175/ 2009JAS3022.1.

Wang, L., J. Qu, X. Xiong, X. Hao, Y. Xie, and N. Che, 2006: A new method for retrieving band 6 of Aqua MODIS. IEEE Geosci. Remote Sens. Lett., 3, 267-270, doi:10.1109/ LGRS.2006.869966.

Wang, Z., S. T. Siems, D. Belušić, M. J. Manton, and Y. Huang, 2015: A climatology of the precipitation over the Southern Ocean as observed at Macquarie Island. J. Appl. Meteor. Climatol., 54, 2321-2337, doi:10.1175/JAMC-D-14-0211.1.

Wentz, F. J., C. Gentemann, and P. Ashcroft, 2003: On-orbit calibration of AMSR-E and the retrieval of ocean products. 12th Conf. on Satellite Meteorology and Oceanography, Amer. Meteor. Soc., Long Beach, CA, P5.9. [Available online at https://ams.confex.com/ams/annual2003/techprogram/ paper_56760.htm.]

White, W. B., and J. L. Annis, 2003: Coupling of extratropical mesoscale eddies in the ocean to westerly winds in the atmospheric boundary layer. J. Phys. Oceanogr., 33, 1095-1107, doi:10.1175/1520-0485(2003)033<1095:COEMEI >2.0.CO;2.

Williams, K. D., and Coauthors, 2013: The Transpose-AMIP II Experiment and its application to the understanding of Southern Ocean cloud biases in climate models. J. Climate, 26, 3258-3274, doi:10.1175/JCLI-D-12-00429.1.

Wilson, T. W., and Coauthors, 2015: A marine biogenic source of atmospheric ice-nucleating particles. Nature, 525, 234-238, doi:10.1038/nature14986.

Wind, G., S. Platnick, M. D. King, P. A. Hubanks, M. J. Pavolonis, A. K. Heidinger, P. Yang, and B. A. Baum, 2010: Multilayer cloud detection with the MODIS near-infrared water vapor absorption band. J. Appl. Meteor. Climatol., 49, 2315-2333, doi:10.1175/2010JAMC2364.1.

Wofsy, S. C., 2011: HIAPER Pole-to-Pole Observations (HIPPO): Fine-grained, global-scale measurements of climatically important atmospheric gases and aerosols. Proc. Roy. Soc. London, 369A, 2073-2086, doi:10.1098/rsta.2010.0313.

Wolters, E. L. A., H. M. Deneke, B. J. J. M. van den Hurk, J. F. Meirink, and R. A. Roebeling, 2010: Broken and inhomogeneous cloud impact on satellite cloud particle effective radius and cloudphase retrievals. J. Geophys. Res., 115, D10214, doi:10.1029/ 2009JD012205.

Wood, R., D. Leon, M. Lebsock, J. Snider, and A. D. Clarke, 2012: Precipitation driving of droplet concentration variability in marine low clouds. J. Geophys. Res., 117, D19210, doi:10.1029/ 2012JD018305.

Xie, S.-P., 2004: Satellite observations of cool ocean-atmosphere interaction. Bull. Amer. Meteor. Soc., 85, 195-208, doi:10.1175/ BAMS-85-2-195.

Xu, K.-M., and A. Cheng, 2013: Evaluating low-cloud simulation from an upgraded multiscale modeling framework model. Part I: Sensitivity to spatial resolution and climatology. J. Climate, 26, 5717-5740, doi:10.1175/JCLI-D-12-00200.1.

Zábori, J., R. Krejci, A. M. L. Ekman, E. M. Mårtensson, J. Ström, G. de Leeuw, and E. D. Nilsson, 2012: Wintertime Arctic 
Ocean sea water properties and primary marine aerosol concentrations. Atmos. Chem. Phys., 12, 10 405-10421, doi:10.5194/acp-12-10405-2012.

, J. Ström, P. Vaattovaara, A. M. L. Ekman, M. E. Salter, E. M. Mårtensson, and E. D. Nilsson, 2013: Comparison between summertime and wintertime Arctic Ocean primary marine aerosol properties. Atmos. Chem. Phys., 13, 47834799, doi:10.5194/acp-13-4783-2013.

Zeng, S., C. Cornet, F. Parol, J. Riedi, and F. Thieuleux, 2012: A better understanding of cloud optical thickness derived from the passive sensors MODIS/AQUA and POLDER/PARASOL in the A-Train constellation. Atmos. Chem. Phys., 12, 11245 11259, doi:10.5194/acp-12-11245-2012.

J. Riedi, C. R. Trepte, D. M. Winker, and Y.-X. Hu, 2014: Study of global cloud droplet number concentration with
A-Train satellites. Atmos. Chem. Phys., 14, 7125-7134, doi:10.5194/acp-14-7125-2014.

Zhang, Z., 2013: On the sensitivity of cloud effective radius retrieval based on spectral method to bi-modal droplet size distribution: A semi-analytical model. J. Quant. Spectrosc. Radiat. Transfer, 129, 79-88, doi:10.1016/j.jqsrt.2013.05.033.

_ and S. Platnick, 2011: An assessment of differences between cloud effective particle radius retrievals for marine water clouds from three MODIS spectral bands. J. Geophys. Res., 116, D20215, doi:10.1029/2011JD016216.

, A. S. Ackerman, G. Feingold, S. Platnick, R. Pincus, and H. Xue, 2012: Effects of cloud horizontal inhomogeneity and drizzle on remote sensing of cloud droplet effective radius: Case studies based on large-eddy simulations. J. Geophys. Res., 117, D19208, doi:10.1029/2012JD017655. 